\title{
MEGALITHIC JAR SITES OF LAOS: A COMPREHENSIVE OVERVIEW AND NEW DISCOVERIES
}

\author{
Dougald O'Reilly ${ }^{1}$, Louise Shewan ${ }^{2}$, Julie Van Den Bergh ${ }^{3}$, Samlane Luangaphay ${ }^{4}$ and Thonglith \\ Luangkhoth $^{4}$
}

\author{
1. School of Archaeology and Anthropology, Australian National University, Canberra, Australia \\ 2. School of Earth Sciences, University of Melbourne, Victoria, Australia \\ 3. Archaeological Assessments Ltd, Lamma Island, Hong Kong \\ 4. Department of Heritage, Ministry of Information Culture and Tourism, Vientiane, Lao PDR
}

Authors 1, 2 contributed equally to this work. Corresponding author: Dougald O'Reilly dougald.oreilly@anu.edu.au

\begin{abstract}
The megalithic jar sites of central Laos remain one of Southeast Asia's archaeological enigmas. These sites, more than 90 known to date, comprise large stone jars, discs, apparent lids and imported boulders located in elevated positions on hillslopes, mountain ridges or saddles. While the sites were first noted in the late 19th century, the first systematic research at these sites only began in the 1930s with the work of Madeleine Colani. Since that time, attempts to understand the culture that created the jars, their distribution and purpose have been limited not least because of the presence of unexploded ordnance (UXO) dating to the conflict in Indo-China in the 1960s and '70s. Renewed archaeological research by the authors commenced in 2016. This paper provides an inventory of known sites, matching historical accounts with more recent survey and lastly lists new sites identified in the recent research programme.
\end{abstract}

\subsection{INTRODUCTION}

The megalithic jar sites of northern Laos, found in Xieng Khouang and Luang Prabang Provinces, constitute one of Southeast Asia's archaeological mysteries (Fig. 1). The Plain of Jars is a widely known term which describes only the three best known sites near the provincial capital of Phonsavan but megalithic sites are found widely distributed over $10,000 \mathrm{~km}^{2}$. Ninety-seven known sites comprising jars made of various types of stone including sandstone, breccia, limestone, conglomerate and granite are found located atop hills, or in mountainous locations, often in a saddle.

The earliest published research on these megalithic sites was undertaken by Madeleine Colani (1935) who documented 21 jar sites (Fig. 2) and five sites with 'funerary stones' as well as a number of menhir sites in Hua Phan Province that she felt were separated in time, space and culture from the megalithic jar sites. Colani named the sites she recorded based either on the name of the village closest to the site, by the number of jars or in

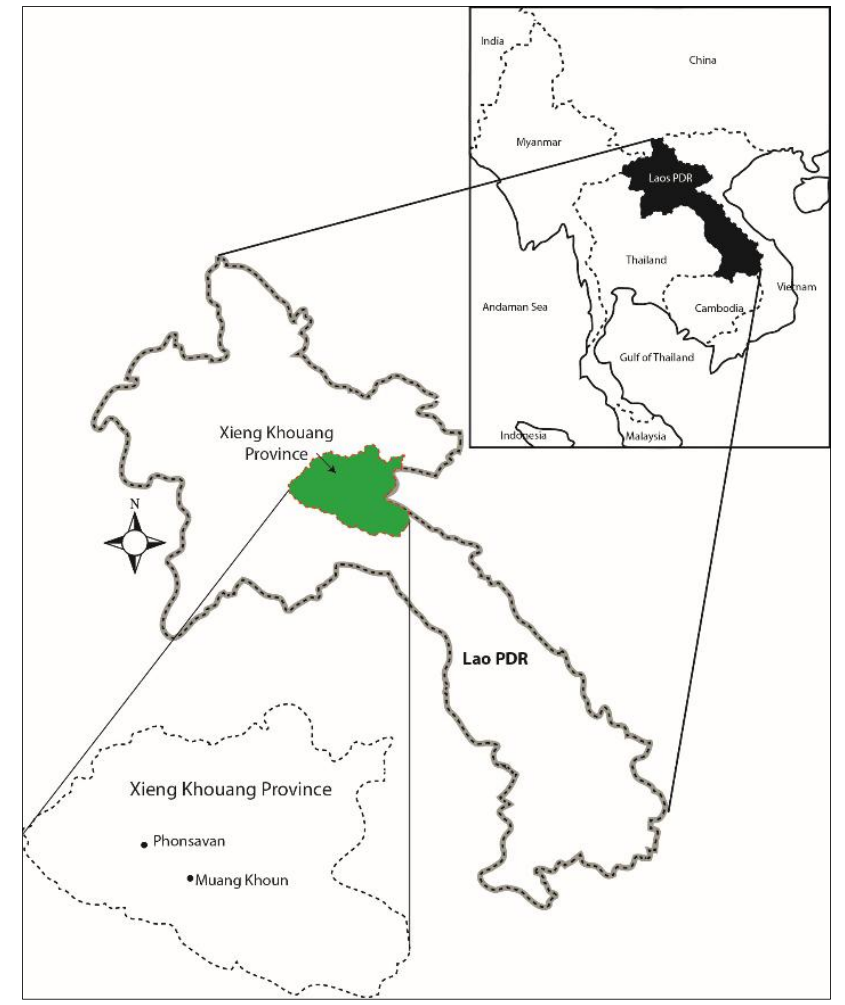

Figure 1. Map showing area of interest.

some cases did not provide any name. Since Colani's seminal research, small projects have focused on the sites near Phonsavan with work undertaken by Ejji Nitta (1996) and Thongsa Sayavongkhamdy et al. (2000). Given the cultural significance of the sites the Lao government have long sought to have the megalithic jar sites listed as UNESCO World Heritage. Safeguarding the Plain of Jars Project (SPJP) was set up in 1998 as a collaborative effort with UNESCO to document jar sites and to prepare for future World Heritage listing. The result of the SPJP, undertaken by Julie Van Den Bergh and Samlane Luangaphay and others between 2001 and 2008, was the geo-location 
and description of 58 jar sites with varying numbers of megalithic jars and other material culture. The sites identified by the SPJP were numbered sequentially as they were documented. Site 1 for example refers to the large jar site near Phonsavan. Further efforts to document jar sites were undertaken by Rosalia Genovese (2015) who created a separate, alphanumeric inventory of jar sites based on perceived function (i.e. jar sites are assigned a $\mathrm{J}$ followed by a number, quarry sites are assigned a Q and QS denotes sites she felt served a dual purpose as quarry and jar site).

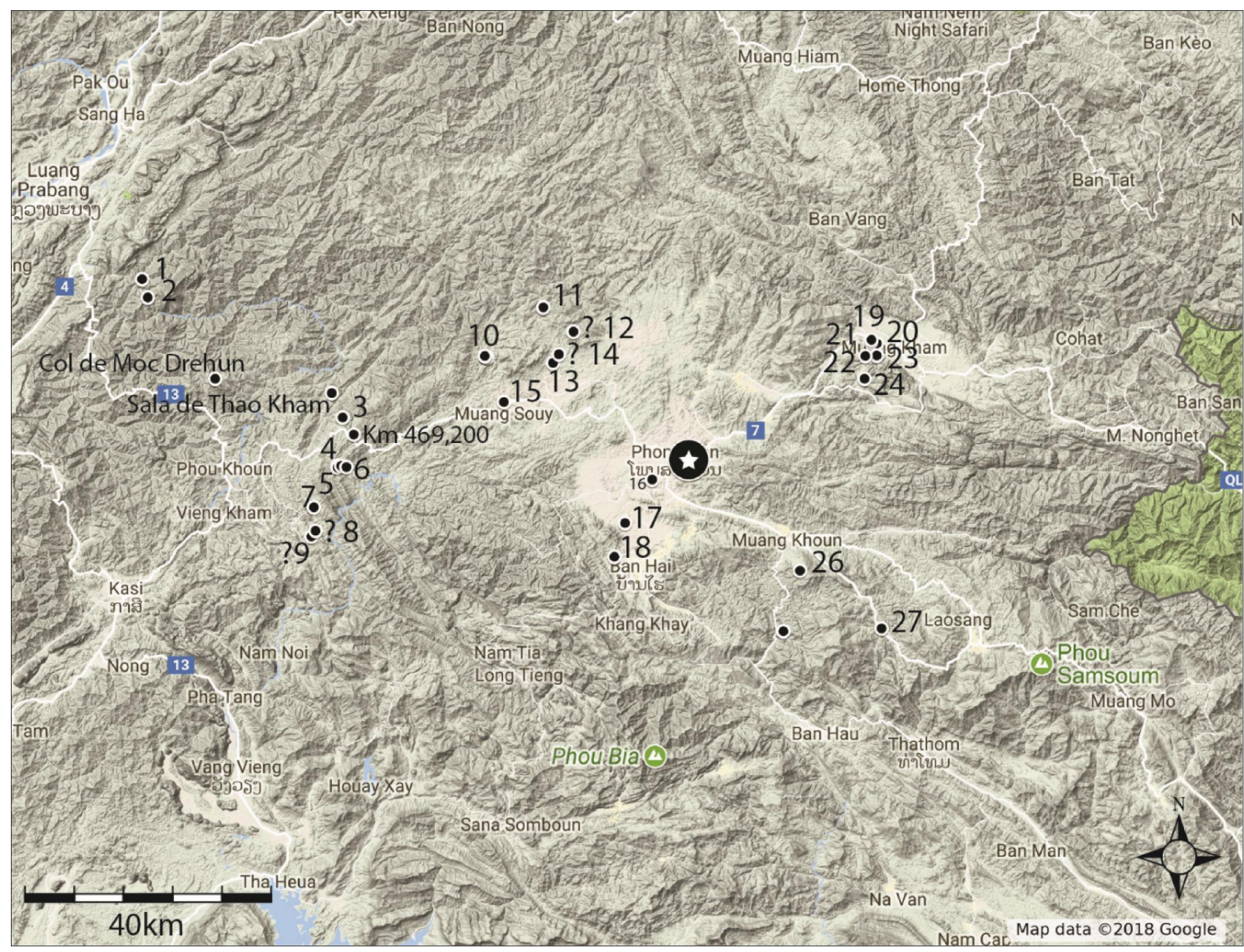

Figure 2. Sites mapped by Colani (1935). Location is unsure where denoted by?

1. In Pen 2. Col de Pou Kassac 3. Kéo Tane 4. Est de Kéo Tane 5.Sud de Kéo Tane 6. Circular Path 7. Eleven Jars 8. San Hin Oume? 9. Sop Nam Miang 10. Ban Xot11. Ban Na Seo 12. Pou Suong? 13.Ban Si 14. Unnamed site? 15. Ban Sak 16. Ban Ang 17. Lat Sen 18. Ban Soua 19. Single jar near Ban Sieng Kieu? 20. Ban Hin 21. Ban Sieng Kieu 22. Group of jars on a plateau? 23. Eight Jars near Ban Nam Ngum? 24. Ban Nam Ngum 25. San Tiau? 26. Na Nong 27. Song Meng?

The result of these multiple naming conventions has led to a degree of confusion regarding the identification of the sites. Here we hope to present an overview of the known megalithic jar sites of Laos using the convention established with the UNESCO-Lao Government survey as it is the most comprehensive and is the one that has been adopted by the Lao Ministry of Information, Culture and Tourism (MoICT), the government body with oversight over archaeological heritage. Herein we present all of the known and recorded sites. The sites documented by the SPJP are presented first and where these sites were also noted by either Colani or Genovese this fact is noted (if no data is recorded, n.d. is inserted). Some sites identified by Genovese and Colani were not included in the original survey and hence have no site number. These sites are presented after the numbered jar sites but exclude sites that Colani (1935) refers to as fields of funerary stones. Sites recently discovered through a joint Lao-Australian research project (Shewan, O'Reilly and Luangkhoth 2016: O'Reilly and Shewan 2016) and two further sites recorded by the Department of Heritage (DoH) are also introduced. 


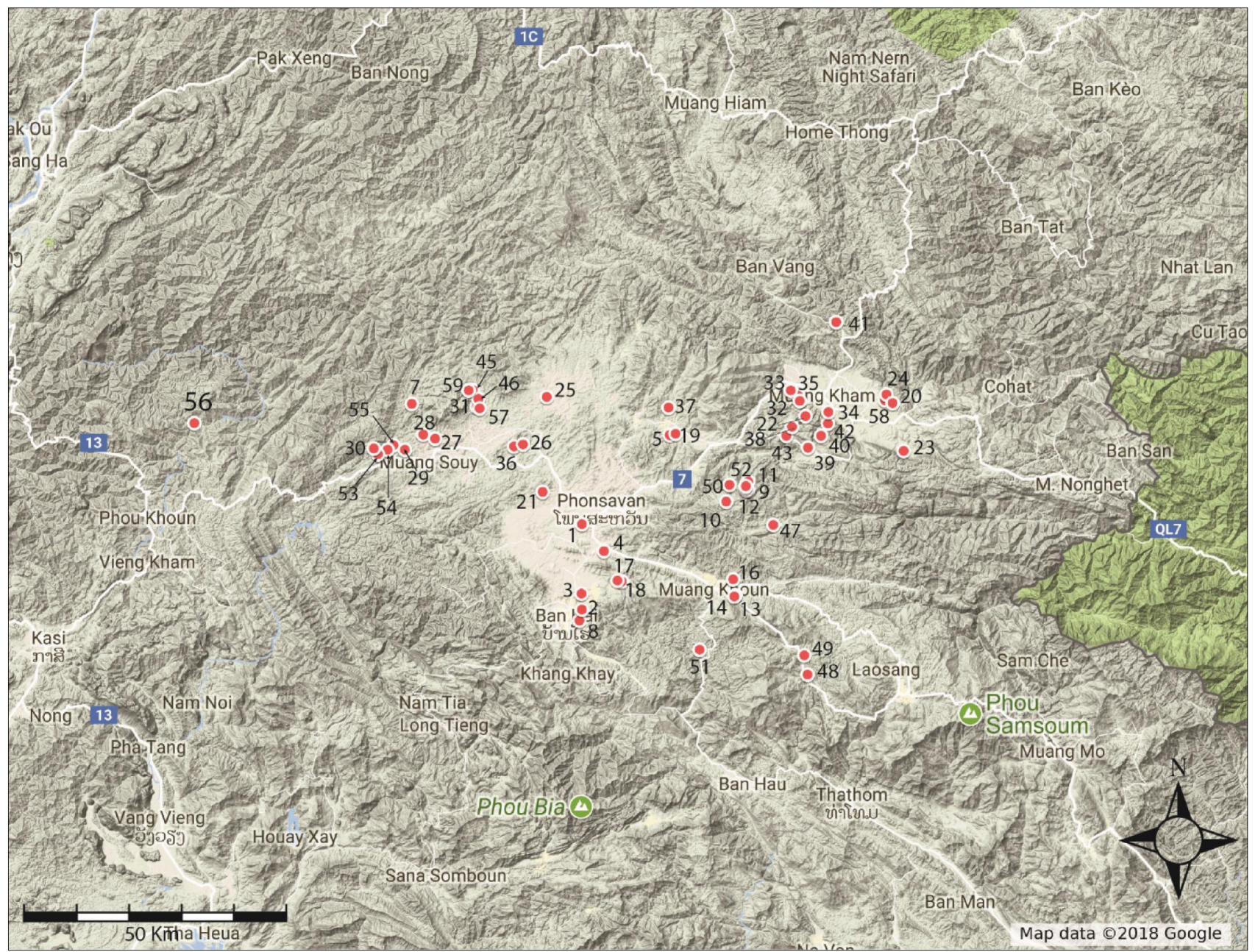

Figure 3. Map of sites mapped by Van Den Bergh and Luangaphay (2008). Numbers reflect site names.

\subsection{METHODOLOGY}

The coordinates used in Colani's 1935 report on the jar sites are provided in the French metric degree system which requires conversion. ${ }^{1}$ Accurately locating the sites identified by Colani (1935) is challenging as even after converting the coordinates some known sites are not accurately positioned. This may be due to a shift in the location of magnetic north since the coordinates were taken or due to data collection error. Many of her sites have no coordinates and must be located by placing her maps as overlays

\footnotetext{
${ }^{1}$ The French system at the time divided a circle into 400 'gradians' rather than using a 360 degree circle. This system expresses latitude from 1-100 gradians (as opposed to $1-90^{\circ}$ ) and longitude from $0-200$ gradians (as opposed to $0-180^{\circ}$ ) rather than coordinates. To convert this to a degrees/minutes coordinate the latitude must be multiplied by 0.9 and longitudes must be multiplied by 0.9 and 2.337231 added to account for the use of Paris as the prime meridian rather than Greenwich. The following formula was used to convert Colani's coordinates; For latitude: $[$ DEGREES $]=[$ GRADS $] * 0.9$, For longitude: $[$ DEGREES $]=$ $\left([\mathrm{GRADS}]^{*} 0.9\right)+2.337231$.
}

in Google Earth and the hand-drawn maps are often variable. An additional issue is matching the description of the sites to present-day conditions often heavily altered in the bombing campaign during the $1960 \mathrm{~s}$ and $70 \mathrm{~s}$.

The survey of megalithic sites, undertaken by a UNESCO-Lao government team mentioned above, focused on identifying sites within Xieng Khouang Province only. The survey was conducted using a stepped approach (Box 2003, Rogers et al. 2003) and as such 84 sites were reported by villagers of which 58 sites were fully mapped including coordinates (Fig. 3) by 2008. 
Locating the sites identified by Genovese (2015) was also problematic as locational details are not included in the published material, perhaps cognisant of the threat of looting and we follow this convention here. The maps provided in Genovese 2015 did, however, allow the authors to locate, with relative accuracy, the sites mentioned (Fig. 4).

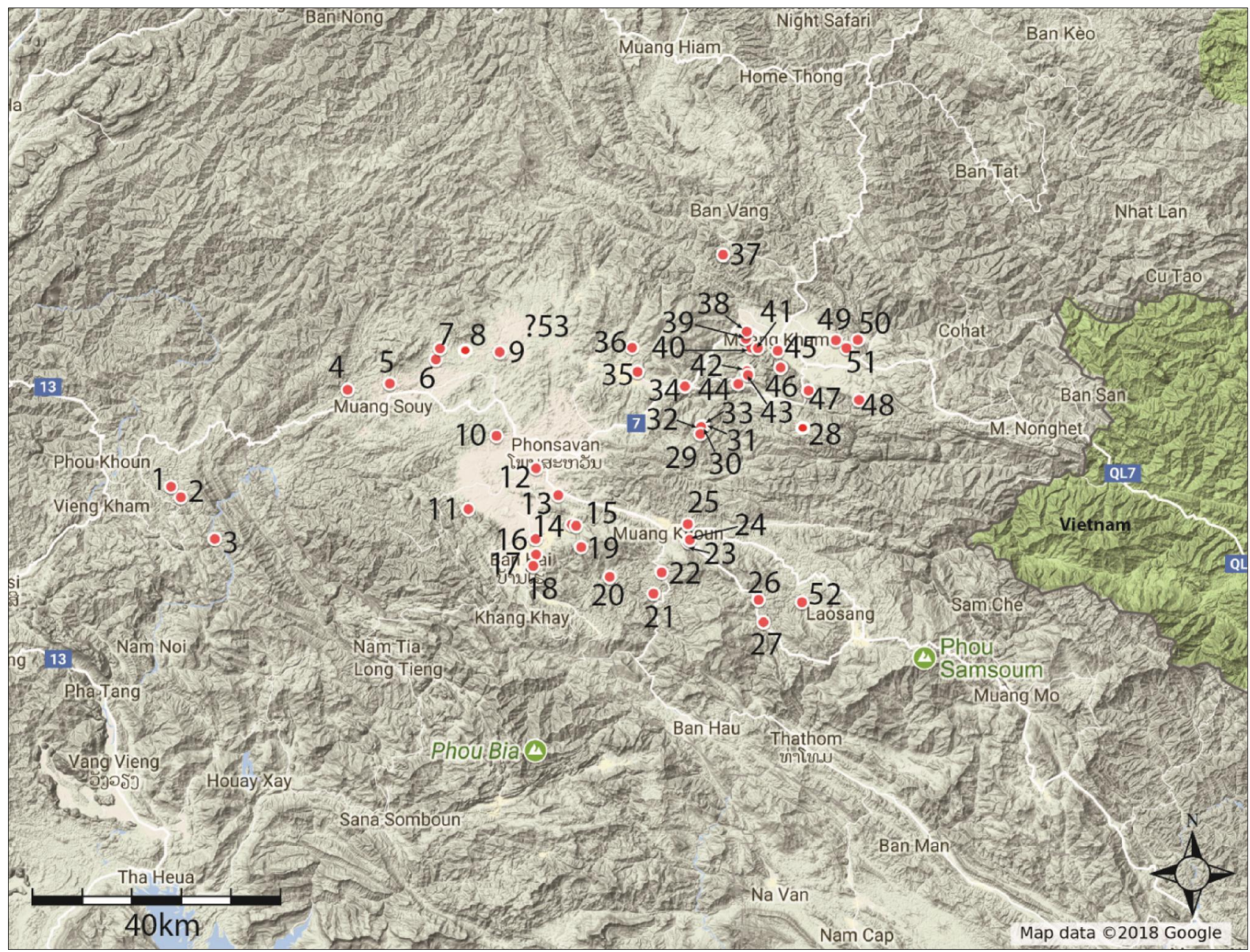

Figure 4. Sites mapped by Genovese (2015).

1. J52 2. J50 3. J51 4. QS42 5. J26 6. J27 7. Ban Na Seo 8. J27 9. J25 10. Q21 11. Ban Phan 12. J1 13. J4 14. Q17 15. Q18 16. J2 17. J3 18. Q8 19. Pho Tsa Nghem 20. Ban Phoung 21. J40 22. QS49 23. QS14 24. QS15 25. J13 26. QS39 27. J38 28. San Tiau? 29. Q10 30. QS11 31. Q9 32. Q54 33. J41 34. J45 35. QS5 36. J31 37. QS34 38. J30 39. QS28 40. QS22 41. J33 42. J32 43. J48 44. J36 45. J29 46. QS35 47. QS47 48. Q23 49. J24 50. J46 51. J20 52. Ban Khek 53. Phou Naséo. All of the numbered sites listed below are documented by SPJP.

Site 1 (Colani: Ban Ang/Genovese: J1)

The first significant research at Ban Ang (now known as Site 1) was initiated by Madeleine Colani in 1931 and continued each year until 1934 (Fig. 5). The results of her research were published in 1935 in a two-volume book. Colani undertook excavations at Site 1 digging around 20 jars. While nothing was found beneath the jars themselves the area surrounding them were rich in finds including ear discs, spindle whorls, glass beads, bronze and iron tools, knives and jewellery. Colani also reported finding terracotta jars used for secondary burial during her excavations. Several of the stone jars contained human remains and glass beads.

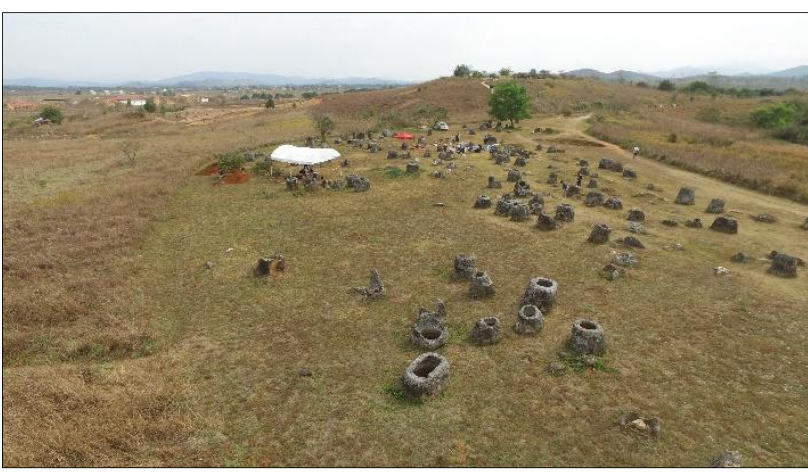

Figure 5. View to the Northeast at Site 1 (Photo: K. Hanus). 
Nitta (1996) undertook some excavations at Site 1 in 1994 publishing only a brief summary. Nitta also inventoried the jars (many are numbered on the inside with white paint) and a map was prepared but never published. Nitta found unburned human remains, iron knives and glass beads as well as a ceramic vessel beneath a flat stone which contained human remains. He estimated the ceramic jar burials dated to the late first millennium $\mathrm{AD}$ to the early second millennium AD.

Three test excavations were conducted by Sayavongkhamdy (n.d.) at Site 1 in 1996. The excavations around the jars revealed burial pits containing human remains and artefacts. In terms of material culture, the excavation revealed seven miniature pots, 28 glass beads a ceramic earring, fragments of bronze, a bronze bell, iron fragments, an iron knife, a bangle and a stone pendant.

Two ceramic vessels were excavated in 2004 by Van Den Bergh (pers. comm.) as part of a rescue operation during the decontamination of the site of UXO.These vessels have since been revealed to contain human remains (Domett and Halcrow pers. comm.).

Excavations were undertaken as part of a collaborative Lao-Australian research effort at Site 1 in 2016 (Shewan, O'Reilly and Luangkhoth 2016; O'Reilly and Shewan 2016; O'Reilly et al. forthcoming). Similar results were obtained during this research to that previously undertaken with evidence of burials, some inside ceramic vessels. The material culture recovered was modest and mirrored that found by Colani and Sayavongkhamdy. As part of this research a survey of the jars at Site 1 revealed that there are 316 jars and 25 discs present which differs in the counts undertaken by SPJP which counted 334 jars and 30 discs and Genovese (2015) who noted 339 jars and 30 discs at the site ${ }^{1}$.

\section{Site 2 (Colani: Lat Sen/Genovese: J2)}

Located about $15 \mathrm{~km}$ to the south of Phonsavan in Phaxay District, Site 2 was known to Colani as the 'Airfield at Lat Sen' (Fig. 6). She describes the site as being atop a small hillock, divided in the middle, as it is today, by a depression. She noted more than 80 jars at the site arranged in two groups to the west and east. Recent documentation (SPJP; Genovese 2015) of the site counted 93 jars, 14 discs and nine stones and a count taken in 2017 noted just 86 jars and 15 discs (Ball pers. comm.). The eastern group comprises 51 jars and seven discs while the western group includes 35 jars and eight discs (Ball pers. comm.). Several

\footnotetext{
${ }^{1}$ Some of the stone jars of Site 1 were moved to decorate Phonsavan cultural hall (now demolished) and a Phonsavan hotel; in addition, it is known that Hmong general Vang Pao gifted the USA a stone jar which currently resides at the Smithsonian Institution and at least 3 stone jars are known in Vientiane. The four jars which remained in Xieng Khouang have been returned to Site 1 . The fragmentary nature of some jars complicates counting. A minimum number of jars, whereby a minimum of $55 \%$ of base remaining counts as one jar was adopted by Safeguarding the Plain of Jars team.
}

of the discs at Site 2 are decorated including one with an anthropomorphic figure in poor preservation.

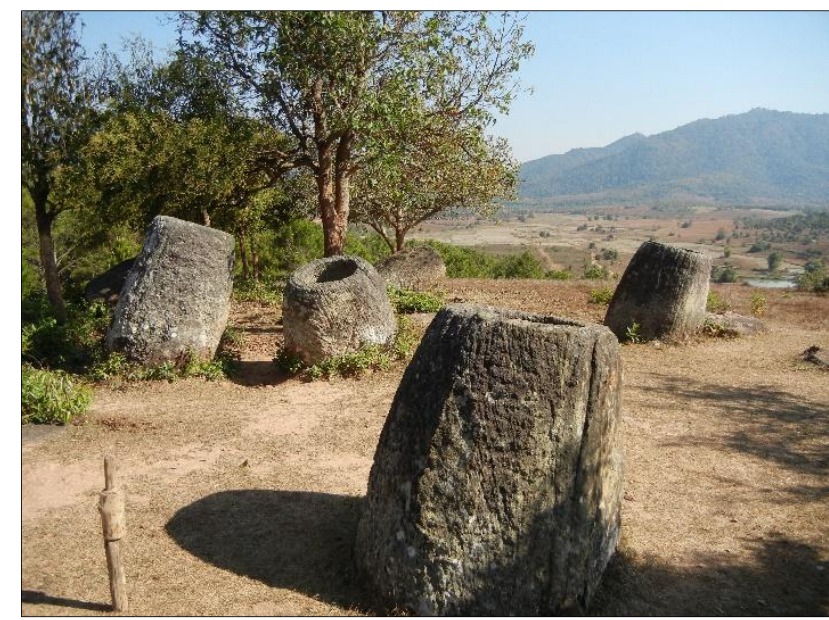

Figure 6. Site 2 (photo: A. Ball)

Colani's excavations at Site 2 revealed findings on the western hillock only including a groundstone disc-ring fragment, three axes, three stone pendants, a grindstone and ceramic sherds. Also uncovered were clay weights or spindles, discs and ear discs as well as spiral pendants, bells and a ring of bronze, glass and carnelian beads. Inside the jars she recorded ceramic sherds and some glass beads and charcoal.

Genovese (2015) notes the jars found on the eastern hill at Site 2 do exhibit more variation in their styles and are more numerous.

\section{Site 3 (Colani: Ban Sua/Genovese: J3)}

Site 3, also known as Ban Xiengdi and, formerly, by Colani as Ban Sua, is located near Site 2 in Phaxai District and comprises, according to Van Den Bergh and Luangaphay (2008) and Genovese (2015) eight groups of jars (Fig. 7). The site is located on a hill slope overlooking a wide plain. There is some discrepancy over the number of groups and jars located at Site 3. Colani (1935) recorded 155 megalithic jars at the main group of Site 3 while Van Den Bergh and Luangaphay (2015) counted 158 jars and 33 discs at the same group and 245 jars and 43 discs arranged in eight groups. Genovese (2015) writes that the site is home to 247 sandstone jars and 45 discs. A recent survey of the site undertaken in 2017 revealed only 240 jars and 41 discs present (Ball, pers. comm.). 


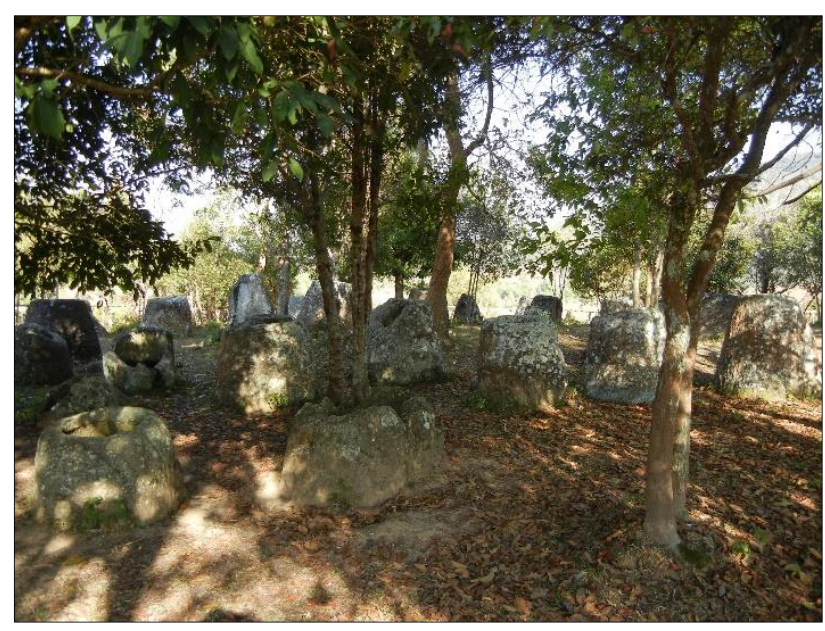

Figure 7. Site 3 (photo: A. Ball)

Colani (1935) excavated at Site 3 finding artefacts similar to those from Site 2, a crude stone ring, stone pestles and a square piece of shale. Inside the jars she found ceramic sherds, an ear disc, glass beads, iron fragments, human bones and teeth. The quarry for this site and Site 2 has been identified as Site 8 , nearly $2 \mathrm{~km}$ south of the site.

\section{Site 4 (Colani:Bergerie?/Genovese:J4)}

This site was documented by the SPJP, recorded as being located close to Ban Lathong in Paek District (Fig. 8). They recorded three badly damaged sandstone jars on a hilltop as well as six boulders. The damage to the site was likely the result of bombing during the Indochinese conflict. Genovese (2015), who records the site as J4, noted three jars and writes that there are remnants of other jars and discs nearby. She also notes that a site she dubbed Q18 (Site 18) may have served as the quarry for this site as the stone is visually similar as it is at QS17 (Site 17) and no other potential sources of stone have yet been located. This site may have been known to Colani as Bergerie (Colani 1935:211; Genovese 2015).

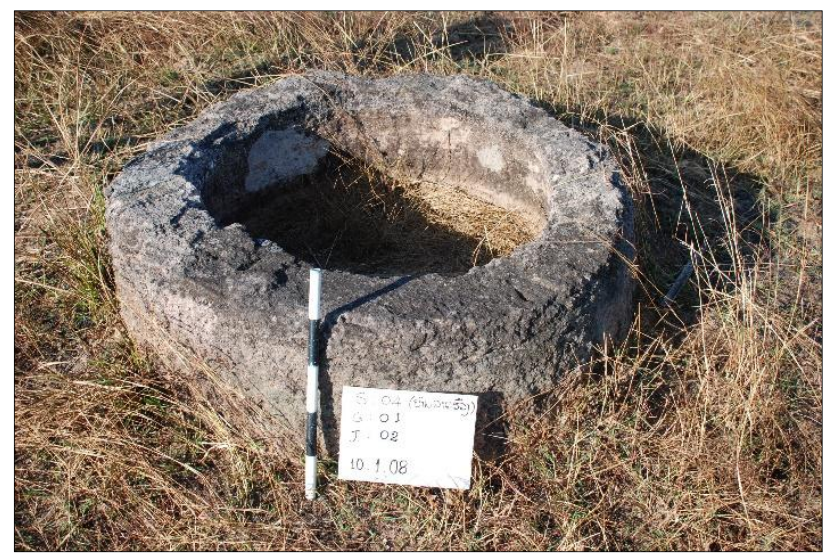

Figure 8. Stone jar at Site 4 (photo: SPJP)

\section{Site 5 (Colani:n.d./Genovese:QS5)}

The SPJP report places the 11 jars and 38 stones of Site 5 near the village of Ban Phaignam (Fig. 9). The site is arranged in two groups, one near the village with three jars and the rest on a hillock nearby. Again the site has been badly damaged by bombing activity and the jars are noted to be heavily damaged. Genovese records the site as QS5 and counts 11 jars arranged in four groups. She records the same three jars in the village and wonders if they were relocated from the nearby hillock. The remaining three groups of jars she places on a hill less than 500m from the village noting that the remaining eight jars comprise both complete and partially carved megaliths as well as an unworked boulder.

The SPJP report omitted a site between Sites 5 and 7 .

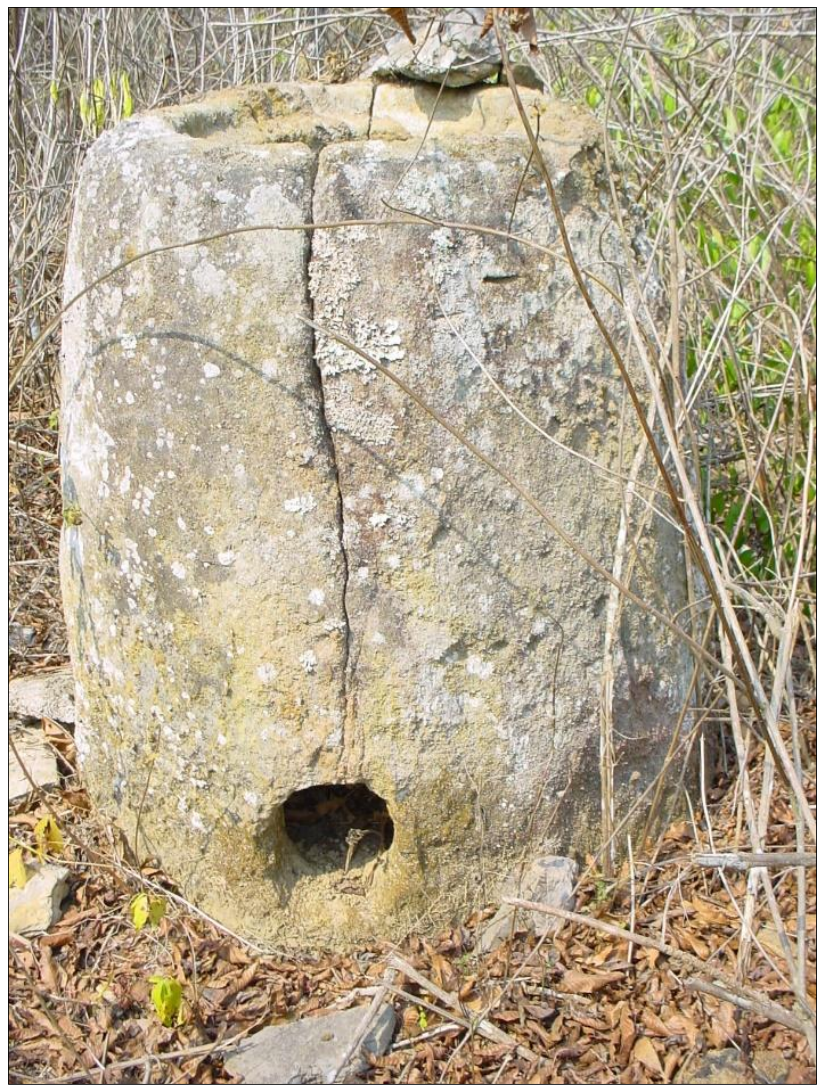

Figure 9. Stone jar at Site 5 (photo: SPJP)

\section{Site 7 (Colani:Ban Xot/Genovese:n.d.)}

Colani documented four jar sites around a village then known as Ban Xot and she excavated around some of the jars in the area. The site was rediscovered during the SPJP and grouped as one site under the name Site 7 (Fig. 10 and 11). Colani notes that the jars at what she called Ban Xot I lie in a field of 'real' boulders of quartz-rich sandstone some of which appear to have been worked. The whole arrangement, including the ten jars, is located in a pass with a view down to the village, presumably indicating they are located on a hilltop (Colani 1935:247). The jars, Colani notes, appear to have been 'worked on the spot' and only 
two had small apertures ${ }^{1}$. At least two subspherical caps were also recorded. Her excavations around the jars revealed a ground stone fragment, glass beads, a bronze spiral bangle, a partial iron ring and some charcoal. Excavations around the stones at the site revealed a broken ceramic vessel and two potsherds.

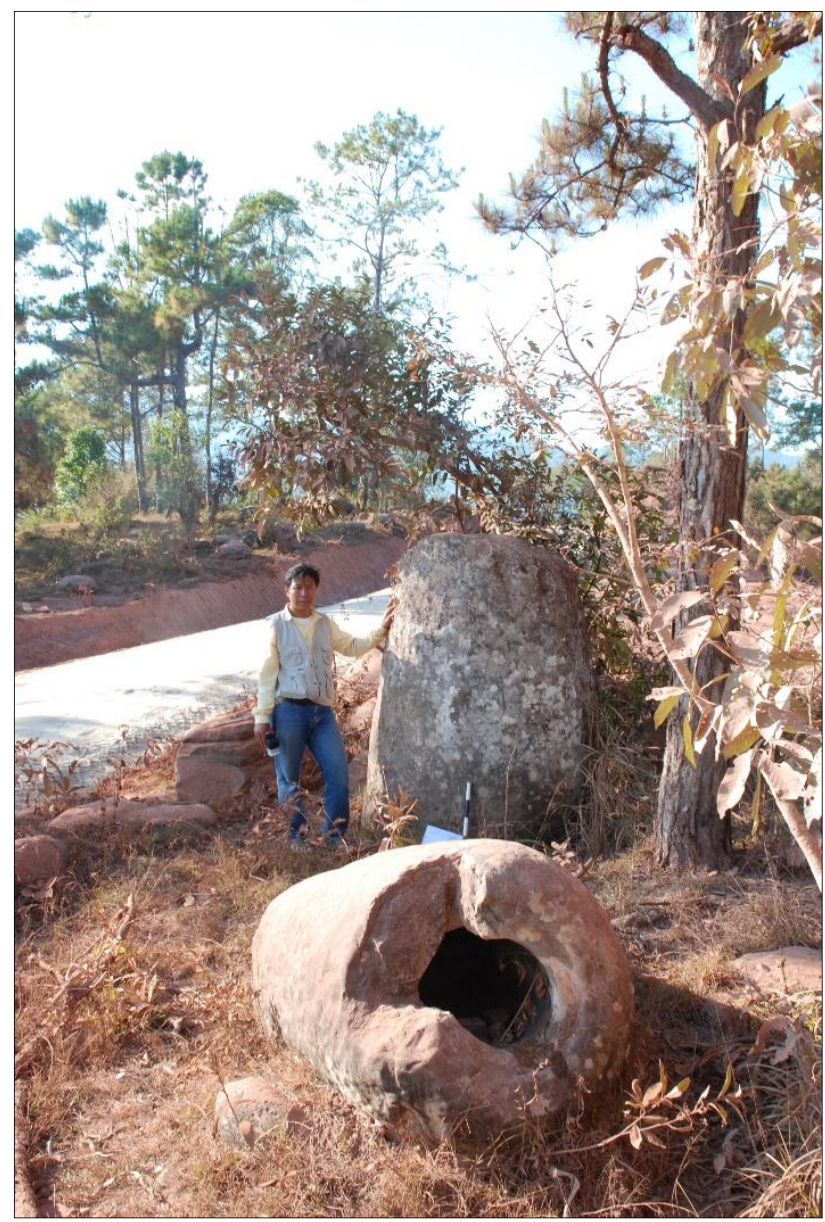

Figure 10. Stone jars at Site 7 (photo: SPJP)

The site labelled as Ban Xot II by Colani (1935:225) is located on the same crest as Ban Xot I, about $50 \mathrm{~m}$ distant but slightly higher in altitude and the site afforded a commendable view of the surrounding area. As at the previous location the ground was covered in boulders and ten jars are dispersed between them, three standing and the others either broken or recumbent. Colani notes one of the jars was surrounded by a ring of burial stones and one recumbent jar (Colani 1935:249). Colani noted that one piece of subspherical sandstone, decorated on one side with a disc, could be a jar cap. The jars at Ban Xot II contained glass bead and excavations around the jars returned a ground stone rectangular pendant, ceramics, glass beads, fragments of bronze and iron and some charcoal.

\footnotetext{
${ }^{1}$ Colani's information is contradictory as she notes that in Jar no.s 1 and 3 she found grey pot sherds.
}

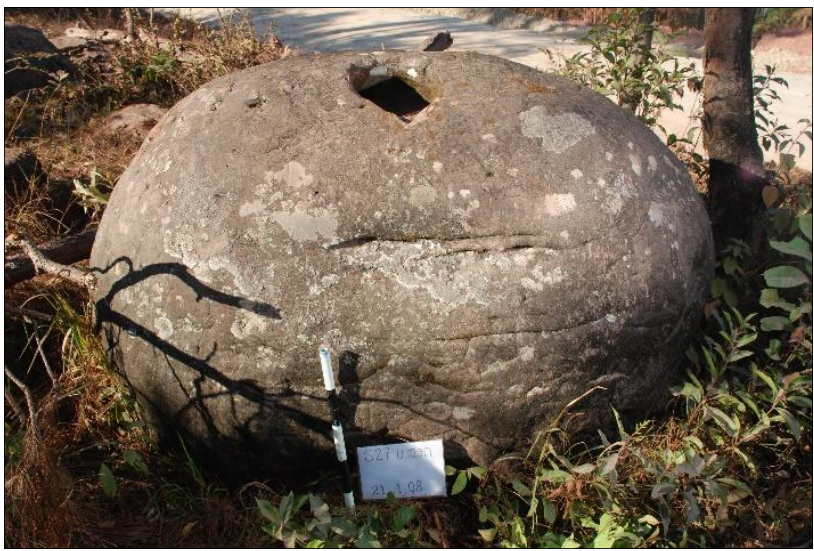

Figure 11. Unusual stone jar at Site 7 (photo: SPJP)

Ban Xot III is recorded as being c. $150 \mathrm{~m}$ from Ban Xot II, comprising about ten quartz-rich sandstone jars (Colani 1935). This site too has the same boulders as the others and ten 'monolithic jars', three of which remained standing and subspherical caps were found nearby. She notes that some of the jars appear to be 'rough-outs' indicating that they may have been carved in situ. The site did boast an unusual artefact in the form of a sub-spherical rock with a concavity similar to the jars forming, what Colani termed as a cross between a monolithic jar and a burial stone. Seven of the ten megaliths at Ban Xot III were recumbent and none of the jars contained artefacts. Colani conducted excavations around the jars and stones finding ceramic sherds, some decorated, many glass beads, small bronze bells, bronze fragments and five spiral iron rings.

The fourth group in the area Colani (1935) calls the 'Group of four jars' which she writes are "no great distance from Ban Xot III" but in a footnote indicates she sometimes refers to the site as Ban Xot IV. This site comprises four jars, two broken, located among quartz-rich sandstone boulders. There were no contents in the jars and no excavations were undertaken at this site.

A disc and 21 jars with small apertures (as opposed to Colani's count of 34) over four groups were recorded by the SPJP. The SPJP report notes that a new road constructed in 2007 displaced a number of jars and 'destroyed the site'. It should be noted that Genovese (2015) does mention Ban Xot but labels it as J26 and places it eight km (based on her map) southeast of Site 7 and very close to Site 27. Genovese's J26 and Site 27 both have 11 jars so it is likely that she has misattributed this as the site Colani named as Ban Xot.

\section{Site 8 (Colani: n.d./Genovese: Q8)}

Site 8 near Ban Xiengdi in Phaxai District does not appear to have been known to Colani. The SPJP report states that the site is in close proximity to Site 3 on a slope and comprises several quarry areas of unfinished, broken and complete jars and Site 8 may represent the quarry for Sites 2 
and 3. This location is recorded as Q8 by Genovese (2015) at which she notes there are eight jars, some of which she feels bear a resemblance to jars found at Site 2 (J2).

Site 9 (Colani: n.d./Genovese:Q9?)

Site 9 was documented by the SPJP near the village of Ban Phakeo not far from Site 52 (J41). The site comprises ten jars of a fine red sandstone and the jars are small compared to the jars found at Site 52 (Fig. 12). Genovese (2015) places a quarry she labels as Q9 near Site 52, stating that it comprises ten sandstone jars and was the quarry for the sites she labels as QS11, J41 (Site 52) and QS44 (Site 10). No coordinates are provided and using a map overlay the location appears to be erroneous.

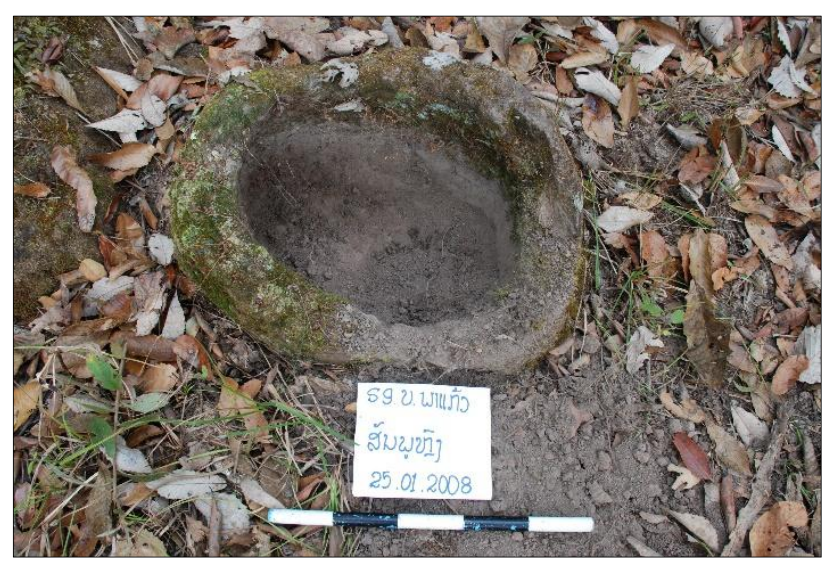

Figure 12. Stone jar at Site 9 (photo: SPJP)

Site 10 (Colani: n.d./Genovese: QS44)

This site is not recorded by Colani and was documented during the SPJP near Ban Phakeo in Paek District (Fig. 13 and 14). The SPJP report notes that there is a disc with a human figure carved upon it and both finished and unfinished jars. Despite the presence of half-finished jars, the site is unlikely to have been a quarry based on the nature of the surrounding rock. Genovese labels a quarrysite that probably equates to Site 10 as QS44, located she says $1 \mathrm{~km}$ south of Site 52 (Genovese's J41) and includes nine jars.

\section{Site 11 (Colani: n.d./Genovese:QS11?)}

Site 11, with two unfinished jars, is located near Ban Phakeo (Site 52). Recorded during the SPJP as having two unfinished jars located on a steep slope. The discoverers note that the site may represent a 'transportation site' where the jars were moved from a quarry and were on the way to a jar site before being abandoned for some reason (Fig. 15). As the jar openings are incomplete it is hypothesised that the jars were to be completed upon arrival at the site.

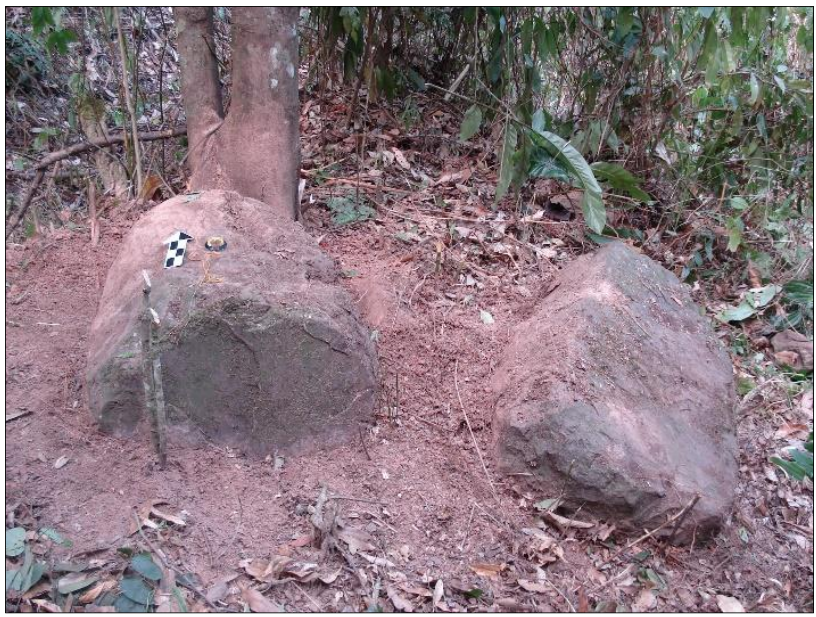

Figure 13. Unfinished stone jars at Site 10 (photo: SPJP)

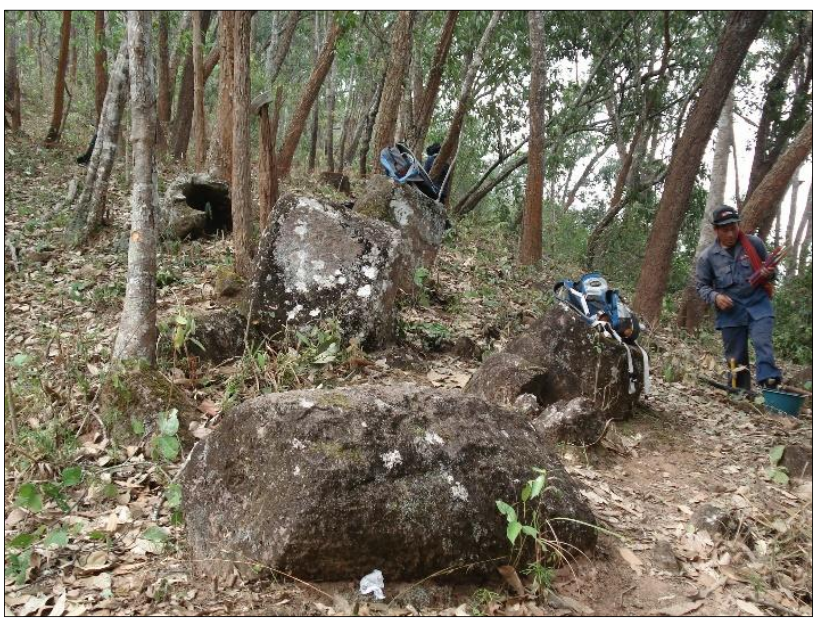

Figure 14. View of Site 10 (photo: SPJP)

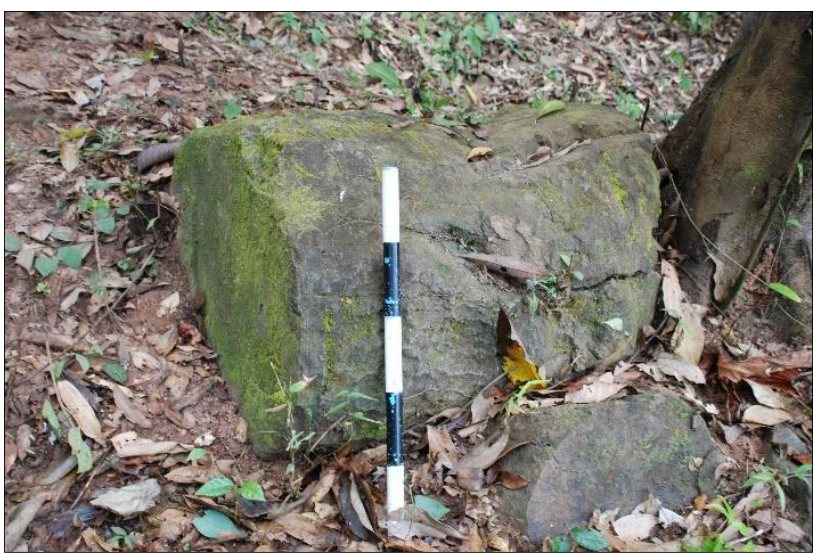

Figure 15. Stone jar at Site 11 (photo: SPJP)

Genovese (2015) has a site labelled as QS11 on her maps but provides no coordinates. Using a map overlay to locate the site places it within the groups of jars at Site 52 which is erroneous. She also records two sandstone jars 
here and no discs noting that this was a quarry-site but provides no further detail.

\section{Site 12 (Colani: n.d./Genovese:QS12?)}

This jar site is located near Ban Pakeo on a mountain ridge and comprises 34 sandstone jars, some unfinished (Fig. 16). Baldock and Van Den Bergh (2009:147-148) however, identify that the in situ rock mass at Site 12 is unsuitable for jar manufacturing. Two discs were also recorded at the site (Fig. 17).

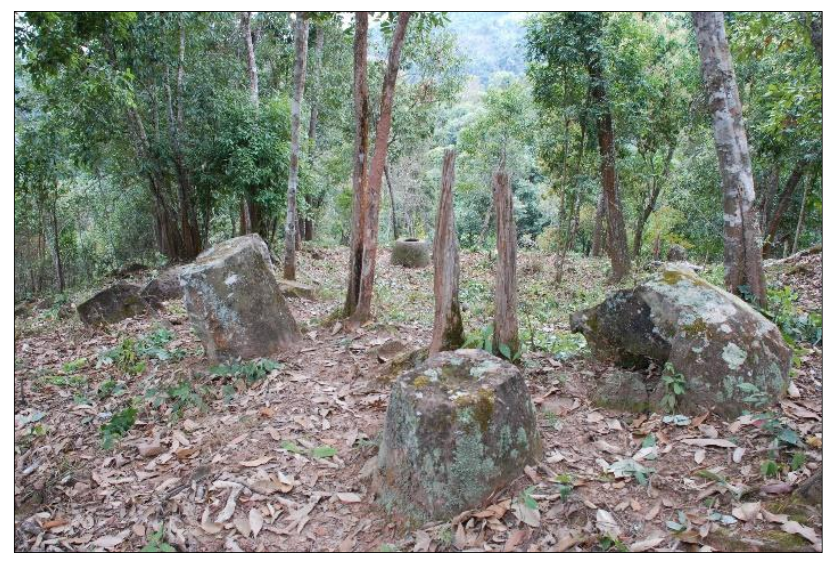

Figure 16. View of Site 12 (photo: SPJP).

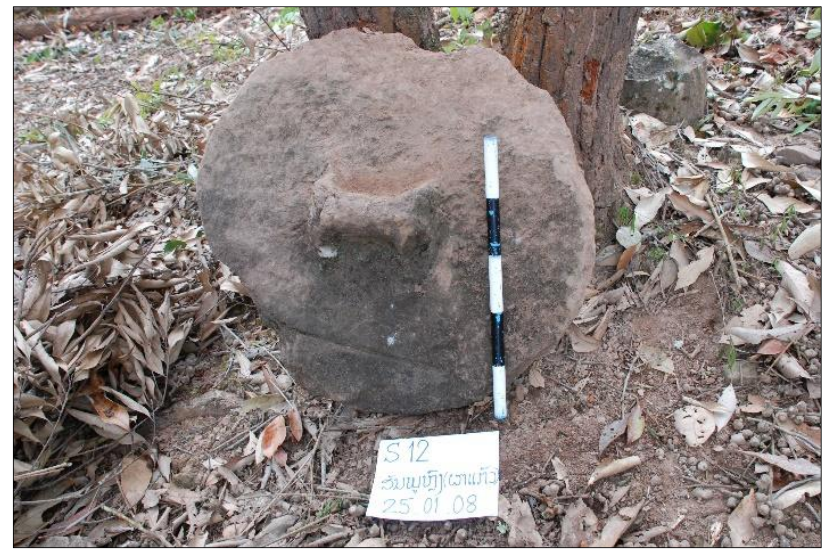

Figure 17. Disc at Site 12 (photo: SPJP).

Genovese (2015) documents a site on a map as QS12 but the location may be erroneous as it appears, based on a map overlay, to sit within the groups of jars at Site 52 . She states that this site comprises 34 jars and two discs of sandstone and the site may have been a source for her QS11 (Site 11), J41 (Site 52) \& QS44 (Site 10). The recent survey by a joint Lao-Australian research team at Site 12 counted 43 jars and rough-outs, six discs and over 90 boulders (Shewan, O'Reilly and Luangkhoth, 2016: O'Reilly and Shewan 2016; O'Reilly et al. forthcoming.).
Site 13 (Colani: Na Nong?/Genovese: J13)

This site is probably what Colani $(1933,1935)$ called $\mathrm{Na}$ Nong where she recorded 34 poorly preserved jars made of granite. Colani records the site as being located about $12 \mathrm{~km}$ from Muang Khoun, the former capital of Xieng Khouang Province. She notes that Na Nong is between two peaks called Pou Kobow and Pou Sao (Colani 1934). Aside from jars Colani found a sub-spherical cap decorated with a human figure which she removed and the present location of this artefact is unknown. Her excavations at Na Nong revealed stone polishing stones, a ceramic jar, ceramic sherds, glass beads and some bronze including a bangle and iron fragments.

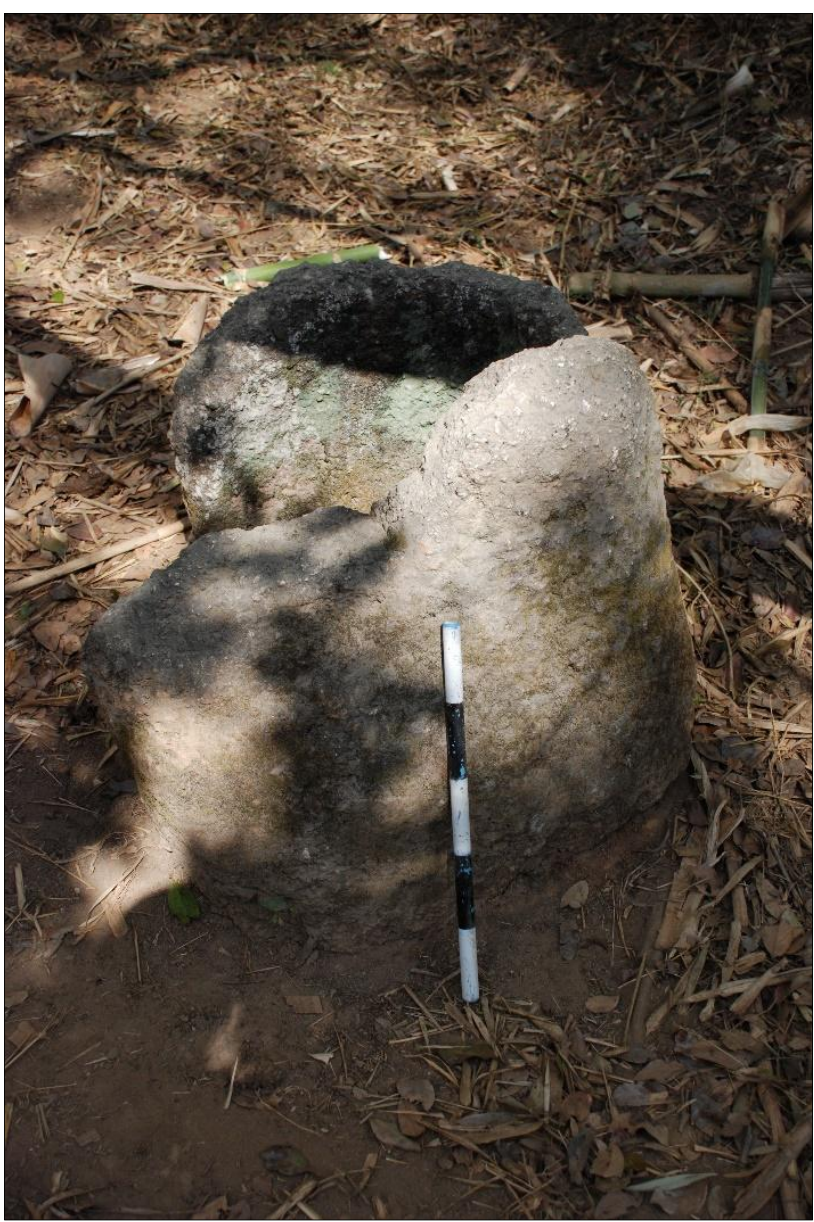

Figure 18. Stone jar at Site 13 (photo: SPJP).

Na Nong was recorded during the SPJP as Site 13 at Ban Thoume, San Phou Naluang in Khoune District where they recorded only three jars, considerably less than Colani reported, a disc and 30 boulders (Fig. 18). They report that there were blocks of granite of considerable size. Site 13 is also recorded by Genovese as J13 and she also reports three jars and a disc being located here. It should be noted that based on Colani's maps, placed as an overlay in Google Earth, the location of Na Nong is roughly 4-7 km south of Site 13 so it is possible that the site Colani called $\mathrm{Na}$ Nong has not been recorded recently. 
Site 14 (Colani: n.d./Genovese: Q14)

The SPJP report states that the site recorded as Site 14 comprises only jar rough outs (no number is provided) and, even though the environs would be suitable for quarrying stone, no direct evidence for quarrying was found. Located near Ban Natad, Khoune District the site is located at the bottom of a hill slope near a stream. Genovese records this site as Q14 and labels it as a granite quarry.

Site 15 (Colani: n.d./Genovese: QS15)

This quarry site is located near Huay Far Par and is thought by Van Den Bergh and Luangaphay (2008) to have served as the source of the granite jars at Site 13 about $2.8 \mathrm{~km}$ to the south. Genovese (2015) does not provide any detail regarding this site but suggests it is a granite quarry and labels it as QS15.

\section{Site 16 (Colani: nd /Genovese: QS16)}

Colani published an account of this site in 1940 and it is further mentioned in Parmentier (1954: 17-18). This site is located near Ban Phai, Khoune District and according to the SPJP report comprises 36 jars, mostly granite in poor condition but one of sandstone (Fig. 19). They also note three stones and a disc at the site which is located on a slight elevation. Genovese (2015) has labelled this site as QS16 and records the same number of jars and discs and places this in a group of sites (mentioned in the preceding site description).

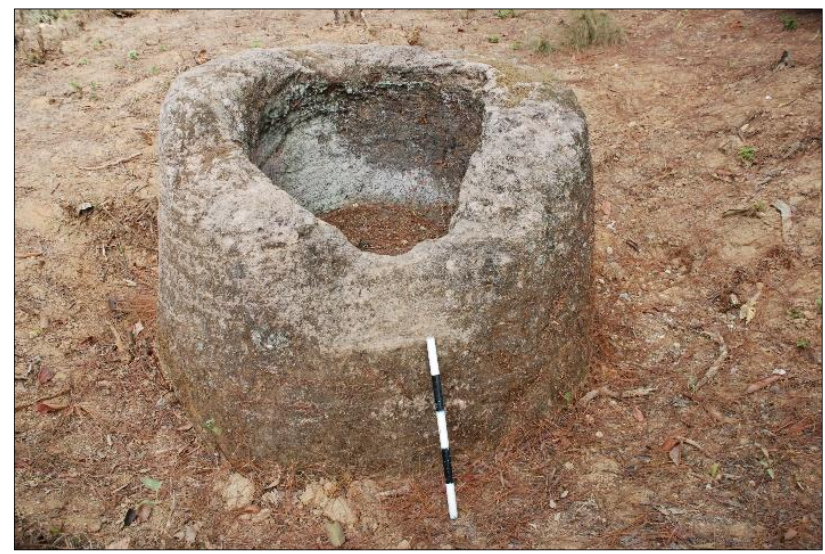

Figure 19. Stone jar at Site 16 (photo: SPJP).

Site 17 (Colani: n.d./Genovese: QS17)

Located in Ban Bouatai in Khoune District, Site 17 was not recorded by Colani. The site, according to the SPJP report comprises five groups of mostly broken sandstone jars (Fig. 20). The first group has nine jars and four discs and funerary marker, the second, six jars, the third, 20 jars and 42 stones while groups four and five have one jar each, totaling 37 jars and four discs. The largest of the jar groups is located on a small rise. Genovese notes that her QS17 is part of a group including J4 (4) and Q18 (18) and she feels that this site is a possible source of the stone for the jars located at Site 4.

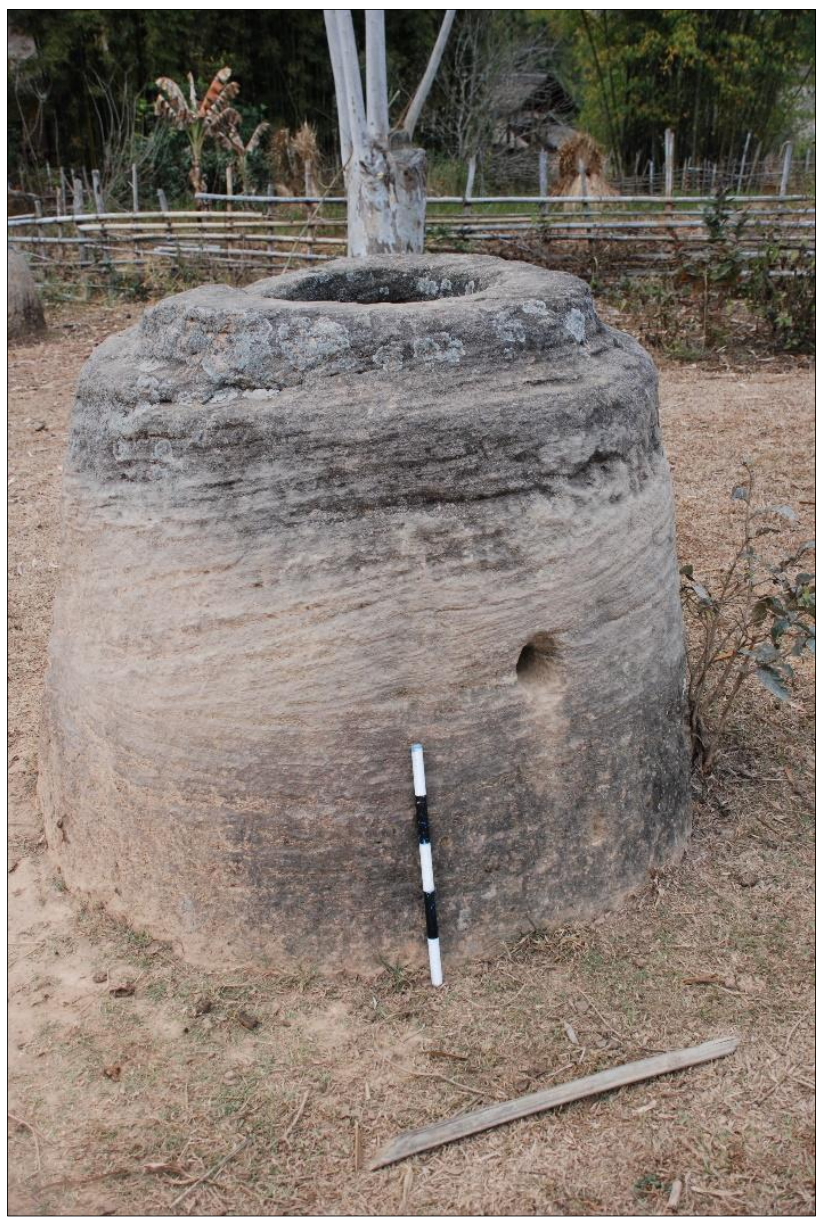

Figure 20. Stone jar at Site 17 (photo: SPJP).

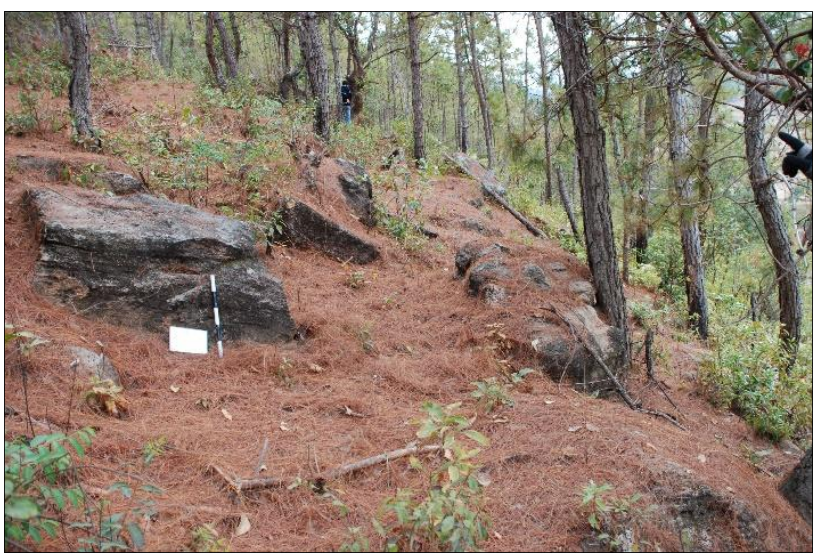

Figure 21. View of Site 18 (photo: SPJP).

Site 18 (Colani: n.d./Genovse: Q18)

Site 18, a quarry, is located near Ban Buatai and Phou Hin Mong in Khoune District on the slope of a hill (Fig. 21). According to Baldock and Van Den Bergh (2009:149) there is evidence for the extraction of maximum 57 jars from the quarry. The 37 jars recorded at Site 17 and a further eight found at Site 18 support the evidence (Van Den Bergh and Luangaphay 2008). Genovese (2015), based on 
maps in her thesis, has the same location for this site and records eight sandstone jars.

\section{Site 19 (Colani: n.d./Genovese:n.d.)}

Located in Paek District, Site 19 comprises a single broken jar which sits in front of a house in the village of Ban Khangvieng.

\section{Site 20 (Colani: n.d./Genovese:J20/J24)}

This site is comprised of four groups of jars, 21 in total, fashioned from conglomerate (Fig. 22). Groups 1, 2, 3 and 4 comprise eight, six, two and five jars respectively. Van Den Bergh and Luangaphay (2008) report the jars to be in very fragmented condition sitting atop a hill about $2 \mathrm{~km}$ from the village of Ban Hai. Genovese (2015) also records 21 jars at this site. One of the groups (Group 4) recorded in the SPJP report seems to be identified as J24 by Genovese (2015) while Genovese's J20 corresponds to Site 20, Groups 1, 2 and 3.

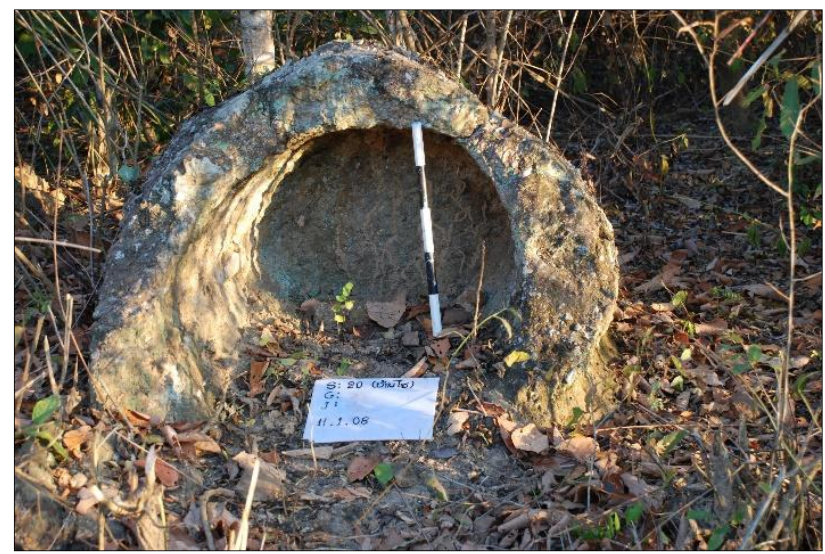

Figure 22. Stone jar at Site 20 (photo: SPJP).

Site 21 (Colani: n.d./Genovese: Q21)

Phu Keng Quarry, labelled as Site 21 in the SPJP report, covers about 20 ha on a mountain side and is likely to have served as the source for the jars at Site 1 c. $9 \mathrm{~km}$ distant (Fig. 23 and 24). During their survey they recorded 23 jars on the steep slopes and lower down the mountainside but there are likely many more. Survey is dangerous as the site is heavily contaminated with UXO. Genovese (2015) concurs that this is likely the quarry for the sandstone jars at J1 (Site 1) noting that the source of the conglomerate jars at Site 1 has yet to be determined.

\section{Site 22 (Colani: Ban Hin/Genovese: QS22)}

Colani (1935, v2:242) mentions the site of Ban Hin, now Site 22 as being located $2 \mathrm{~km}$ from Ban Hin or Ban $\mathrm{Na}$ Hin where she found sixteen jars, two recumbent, on the crest of a hill. She reports the jars are fashioned from quartz-rich sandstone and are rather weather-worn. There was, at the time of her visit, a spherical cap-stone at the site as well. Her excavations at the site revealed that the jars were set "deep into the earth" and some sparse artefacts were recovered including two ground stone pendant discs, ceramic sherds and fragments of bronze and iron.

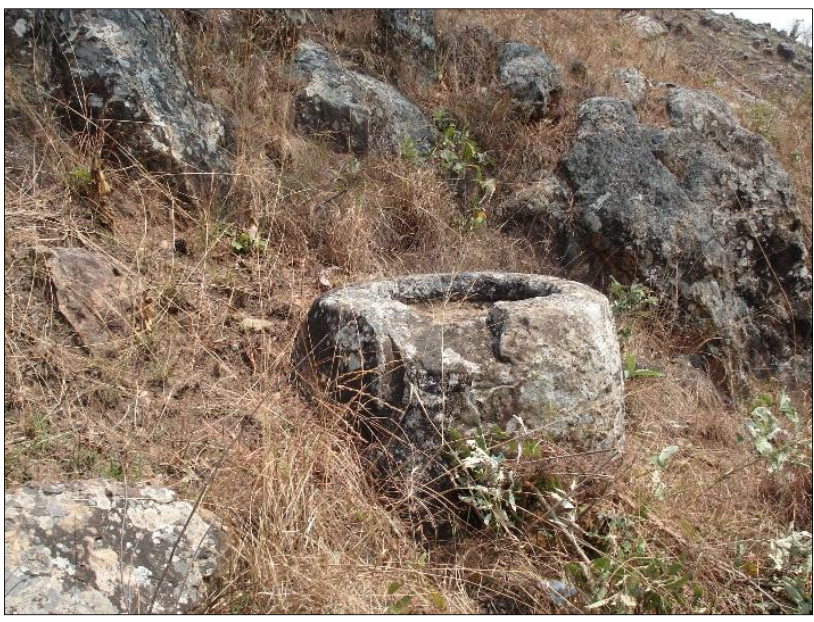

Figure 23. Stone jars at Site 21 (photo: SPJP).

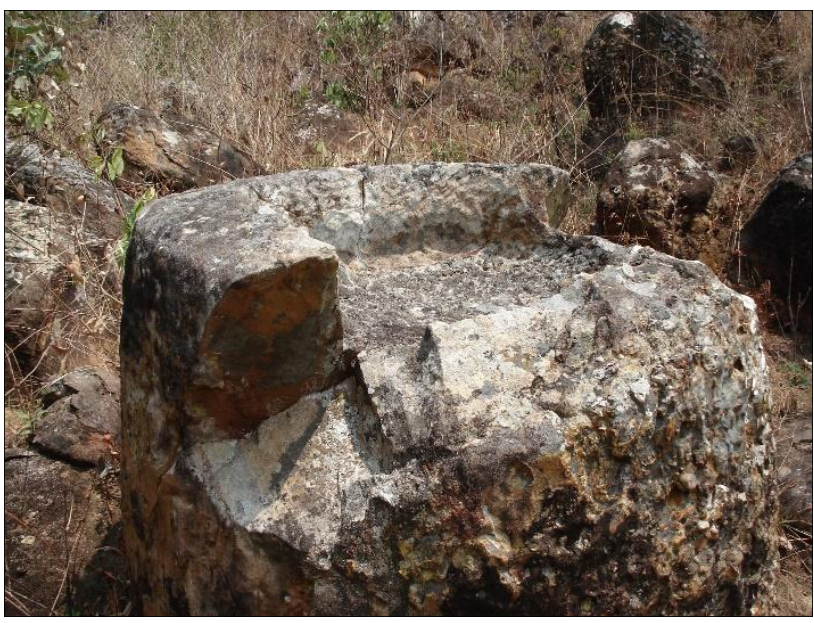

Figure 24. Unfinished stone jar at Site 21 (photo: SPJP).

This site, labelled as Site 22 in the SPJP report, is in Ban Hin in Kham District and comprises a single group of ten jars with nine stones and a disc was also recorded. Genovese equates this site with Colani's (1935, v1: 6, 14, 113, 131, 144, 150, etc.) Ban Hin and writes that she found the same domed stone disc noted by Colani on her visit there. She also noted ten sandstone jars at the site.

\section{Site 23 (Colani: n.d./Genovese: QS23)}

A jar site comprising four groups of jars, 32 in total, was identified near Ban Nam Hom in Kham District. The SPJP report indicates that the groups of conglomerate and breccia jars are located close to each other on two spurs overlooking the Muang Kham valley (Fig. 25 and 26). Site 23 is notable due to the presence of breccia as this is the only documented case to date. Six stones were recorded here. Genovese (2015) labels this site as QS23 but provides scant detail on the site which she says is home to 28 jars. 


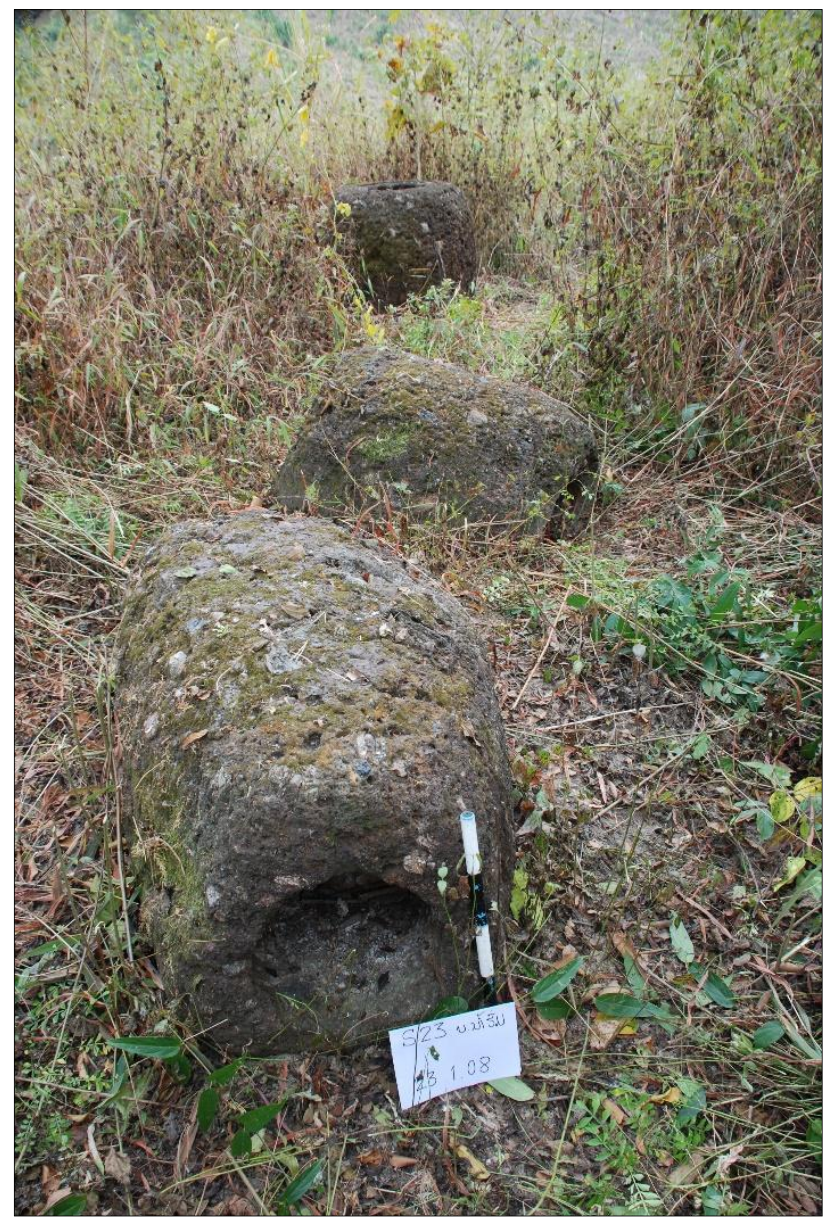

Figure 25. Stone jars at Site 23 (photo: SPJP).

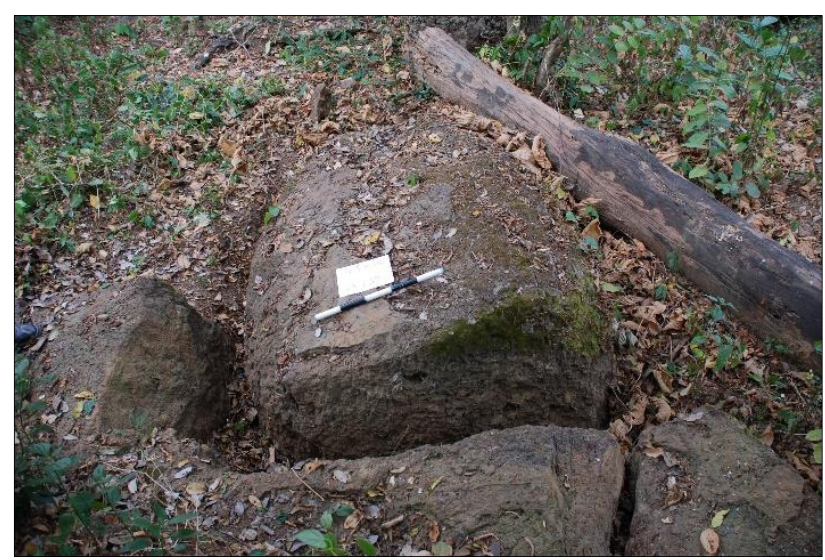

Figure 26. Partly quarried stone jar at Site 23 (photo: SPJP).

Site 24 (Colani: n.d./Genovese:n.d.)

This site located near Ban Phiangxai in Kham District comprises two jar groups with three conglomerate jars in poor condition according to the SPJP report (Fig. 27).

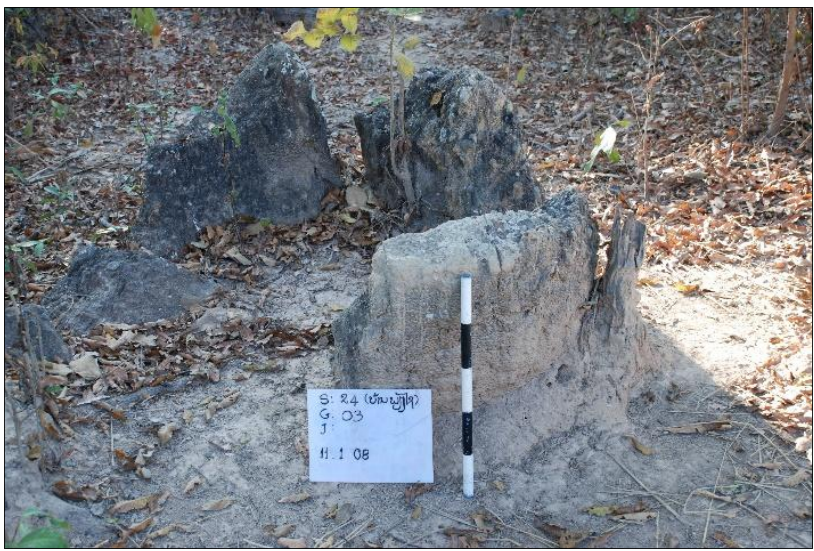

Figure 27. Eroded stone jar at Site 24 (photoSPJP).

Site 25 (Colani: n.d./Genovese: J25)

Site 25, near Ban Songhak in Phoukout District comprises 40 jars in five groups according to the SPJP report (Fig. 28). The first group contains 32 jars and the other eight jars are distributed among the remaining groups. The sandstone jars are in relatively good condition even though the site was the scene of heavy combat during the Indochina war and entrenchments can still be seen around the jars (Fig. 29). Baldock and Van Den Bergh (2009:149-150) note the presence of some andesite roughouts that possibly were abandoned as too difficult to work. Genovese (2015) records 24 jars at this site and also mentions the andesite boulders adding that this site may have been documented by Parmentier (1954:40) and known to him as Thong Hac. Eight stones were also recorded at the site.

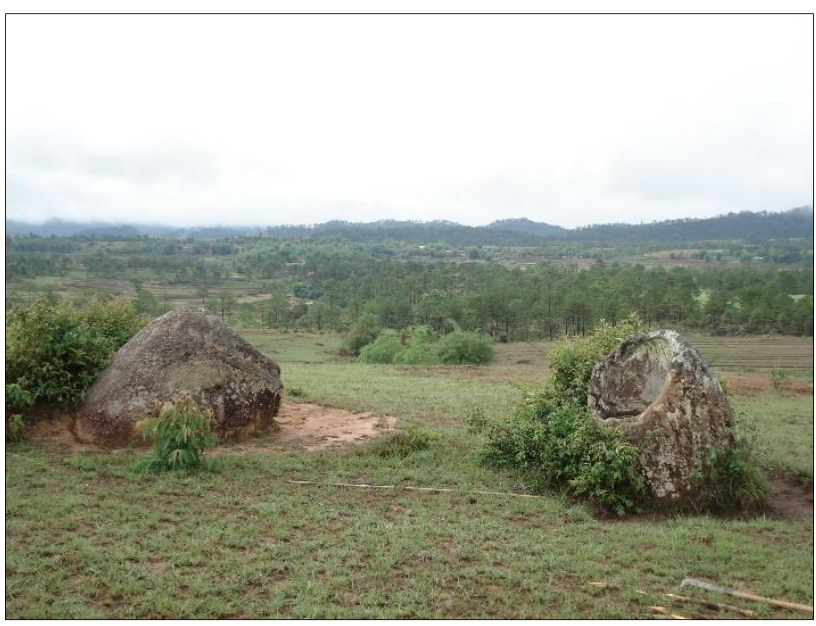

Figure 28. Stone jars at Site 25 (photo: SPJP).

Site 26 (Colani: n.d./Genovese:n.d.)

Site 26 is located near Ban Phouvieng (Nameng) in Phukout district at the foot of Phukout Mountain (Fig. 30). The surrounds were heavily bombed during the Indochina war and the site nearly obliterated but three groups are reported in the SPJP report. Fragments of 11 jars are in one group 
and two single jars comprise the other 'groups'. One disc was also recorded.

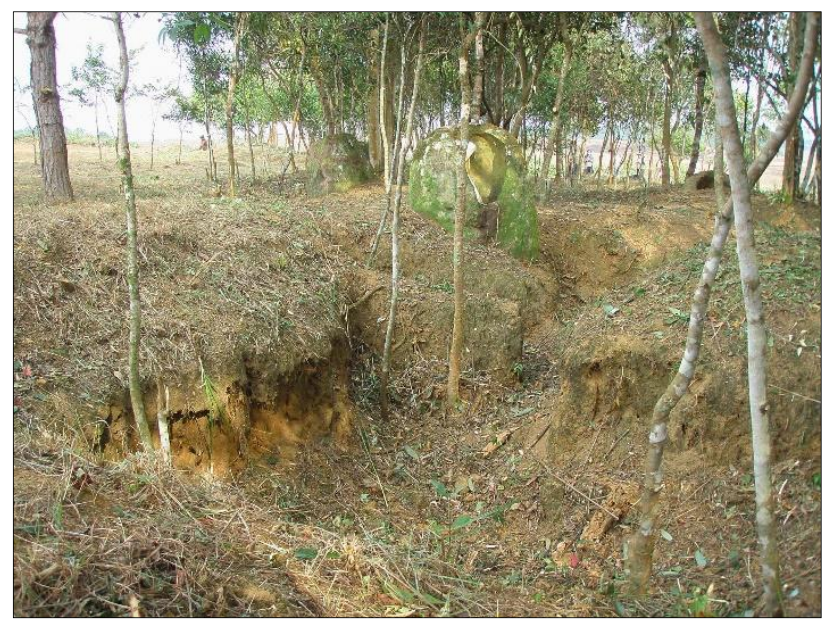

Figure 29. Modern entrenchments at Site 25 (photo: SPJP).

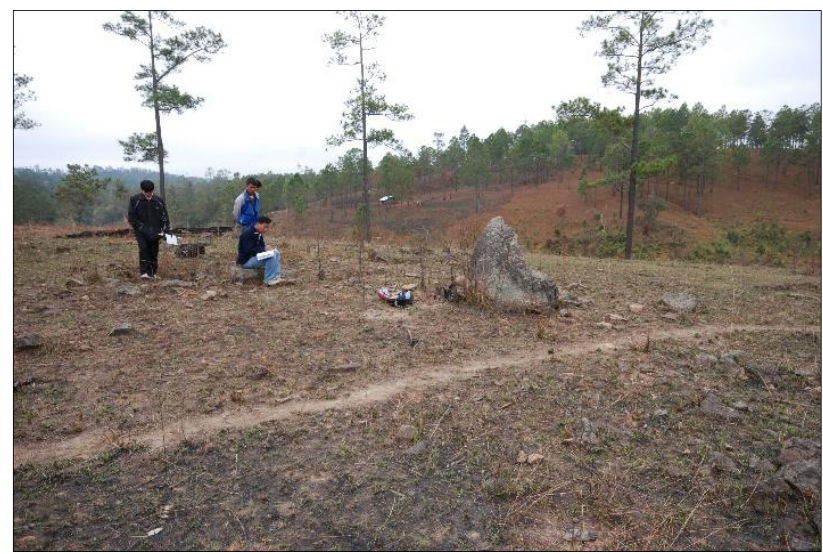

Figure 30. View of Site 26 (photo: SPJP).

Site 27 (Colani: n.d./Genovese: J26)

The SPJP report records this site as being located near Ban Sack or Ban Xot in Phukout District comprising two groups of jars, one with eight and the other with three jars. They also recorded two discs and 16 stones at the site which is situated on a steep-sided hill. Genovese (2015) records this site as being equivalent to Colani's (1935) Ban Xot which is likely erroneous as Colani's Ban Xot more likely equates to Site 7 . Genovese (2015) notes the site comprises 11 sandstone jars and two discs and most of her description for this site is taken from Colani's (1935) description of Ban Xot (probably Site 7).

Site 28 (Colani: isolated jar at Ban Sak/Genovese: n.d.)

It is likely that the site now called Site 28 was visited by Colani $(1935: 246)$ who records a single jar in a pass in the vicinity of Muong Soui, about a kilometer from Ban Sak (Fig. 31). She records magnificent views from the site and undertook excavations around the jar which she describes as being $2.45 \mathrm{~m}$ in height and $2.05 \mathrm{~m}$ in diameter.A polished adze, ceramic fragments, glass beads and fragments of bronze and iron as well as charcoal were recovered in these excavations the depression of which, according to Van Den Bergh and Luangaphay (2008), are still visible. The SPJP report describes one jar of massive proportions and in good condition and notes four stones at the site.

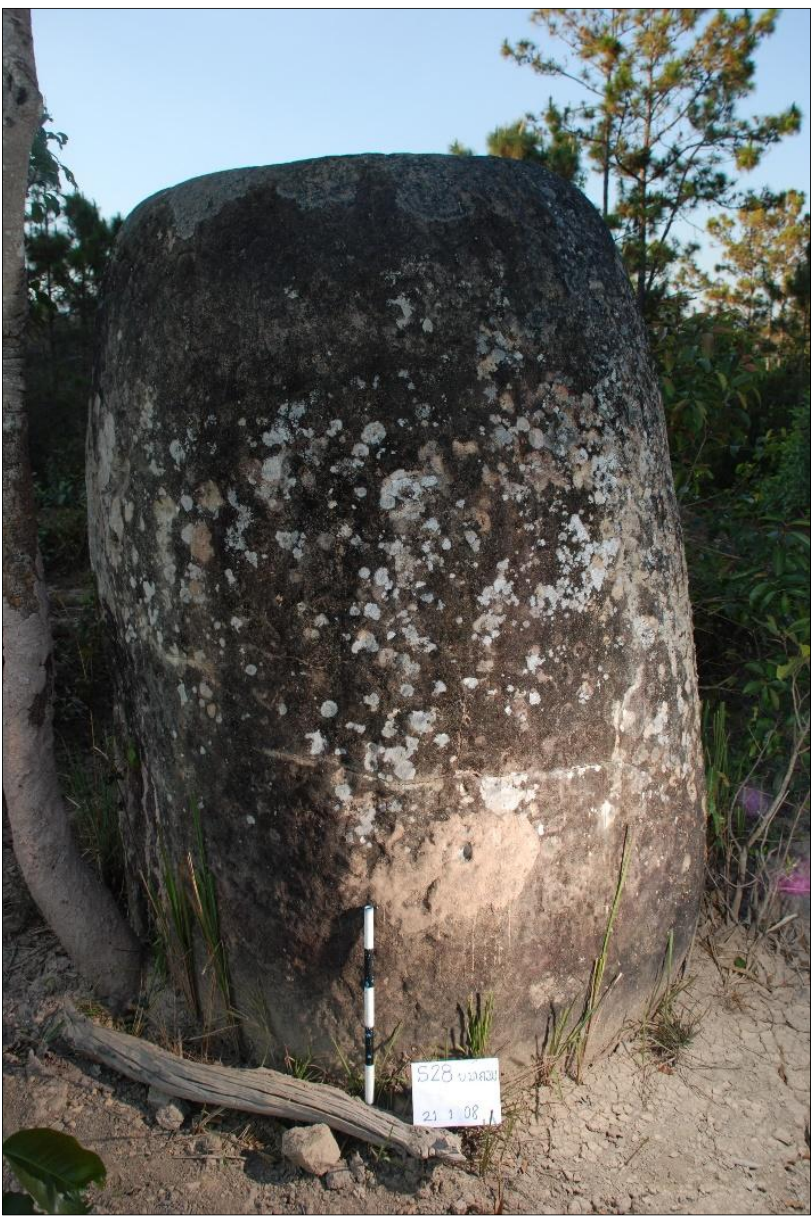

Figure 31. Stone jar at Site 28 (photo: SPJP).

Site 29 (Colani: n.d./Genovese:n.d.)

Site 29, Ban Nam Oc Hou, in Phukout District, comprises two groups of jars, one atop a mountain and the other c. $600 \mathrm{~m}$ distant on a ridge near the village. The SPJP report indicates three sandstone jars, two in one group and one in another and five incomplete jars (Fig. 32).

\section{Site 30 (Colani: n.d./Genovese:n.d.)}

According to the SPJP report, Site 30 is located near Ban Chomsy and San Phou Ten Yang in Phukout District (Fig. 33). The site comprises one group of four sandstone jars located on a mountain ridge. Not far from the jars they recorded four possible funerary stones and a disc (Van Den Bergh and Luangaphay, 2008). 


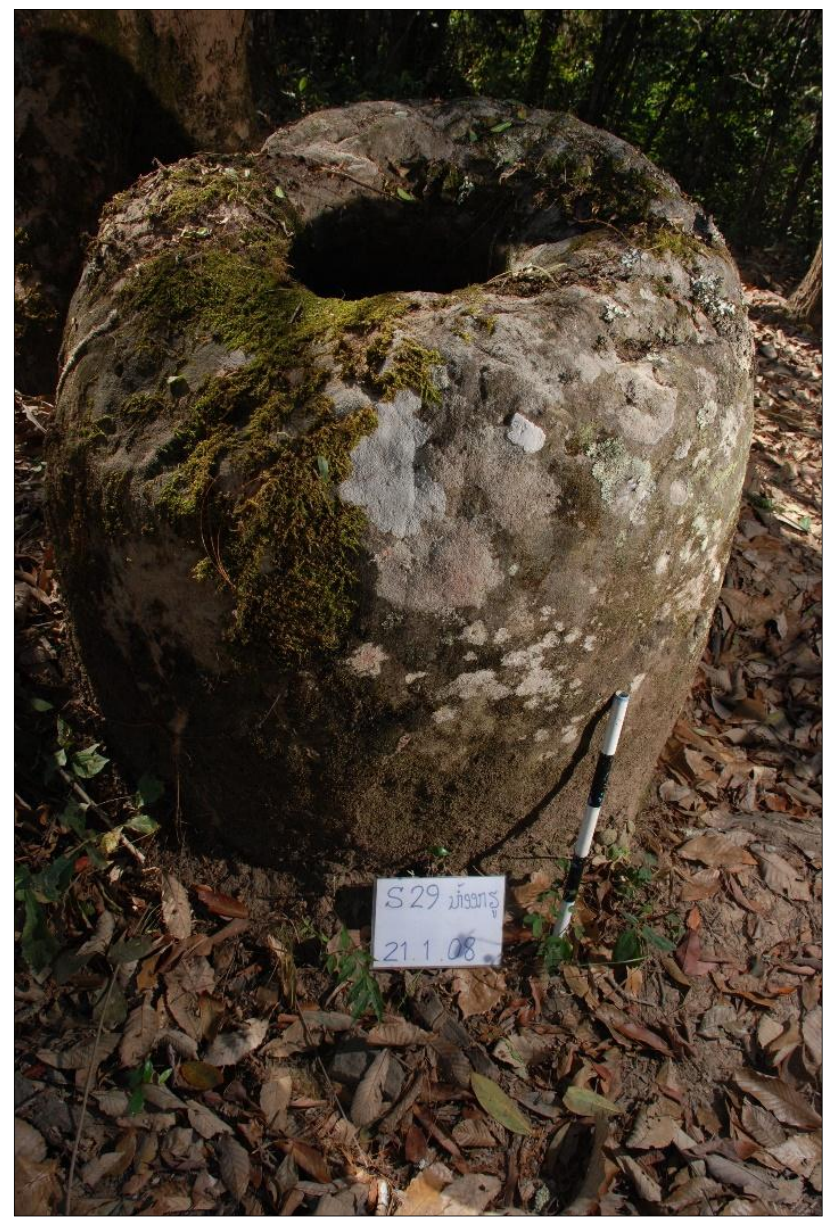

Figure 32. Stone jar at Site 29 (photo: SPJP).

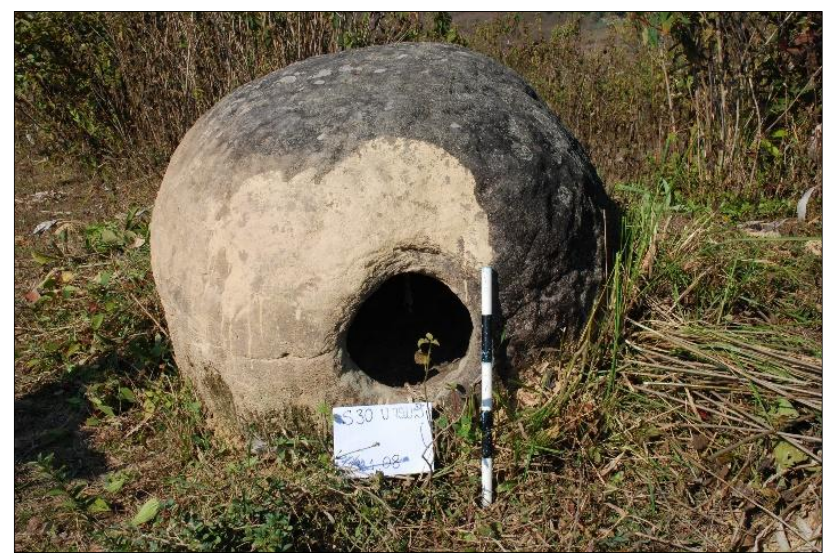

Figure 33. Stone jar at Site 30 (photo: SPJP).

Site 31 (Colani: Ban Si/Genovese: J37)

Colani (1935) documented a site she called Ban Si named for the nearby village at which she recorded two hillocks each with jars and in between two jars, one recumbent. On the eastern hillock she noted a jar with apertures at both ends and ten burial stones. To the west were three large jars, of which one had a double aperture, and more burial stones. Van Den Bergh and Luangaphay (2008) revisited this site, located near Ban Ang and Phu Nabung in Phukout District, and labelled it as Site 31. They note three groups with a total of nine jars, one group boasting five jars and the other two groups, two jars each. The two smaller groups also had discs, two in one of the groups and a single disc in the other. They recognised one jar with a double aperture whereas Colani (1935) recorded two.

The largest of the double aperture jars according to Colani (1935 vol.1:255) was $2.75 \mathrm{~m}$ long and the cavities on both were narrow. Within one of the jars, which Colani describes as a 'dwarf' jar, were found a glass bead and an iron tool (Fig. 34). Her excavations around the jars and burial stones revealed ceramic sherds, a ceramic vessel and a bronze pendant.

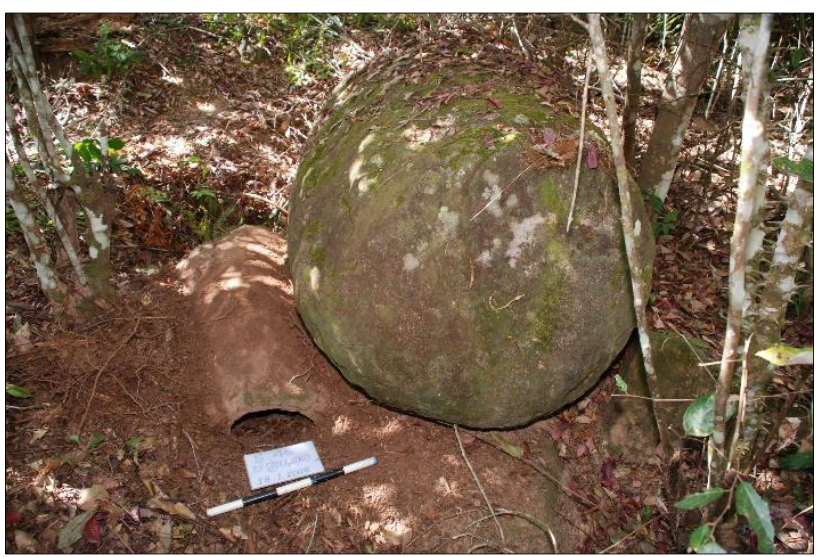

Figure 34. Stone jar with 'dwarf jar' at Site 31 (photo: SPJP).

This site, based on the description by Genovese (2015), is likely to equate to her $\mathrm{J} 27 / \mathrm{J} 37$ although she states $\mathrm{J} 27$ and $\mathrm{J} 37$ are separated by a distance of $1.7 \mathrm{~km}$ both are described with two, double-aperture sandstone jars (2015:112-113). Genovese (2015:164) records four jars at $\mathrm{J} 27$ and eight sandstone jars at J37 (Site 31 is thought to have nine jars) and three discs. She also mentions a dwarf jar nestled next to one of these large jars at J27 and this is described by Colani (1935) for Ban Si which is Site 31 according to Van Den Bergh and Luangaphay (2008).

Site 32 (Colani: Ban Sieng Kieu/Genovese: QS28)

This jar site is listed in the SPJP report as being located in Kham District near the village of Ban Xiengkieu and San Phou Getlin and it may relate to a site mentioned by Colani (1935), Ban Sieng Kieu. Colani (1935:240) mentions that there are 40 megalithic jars at this location on a plateau not far from a village then known as Sieng Kieu, four km west of Ban Ban. The jars are of modest size, the tallest being measured at $1.7 \mathrm{~m}$ but most are $1-1.5 \mathrm{~m}$ tall. Colani also mentions finding three presumed stone lids here, most being concave spherical caps not seen elsewhere. Colani excavated this site finding a groundstone axe, ceramic sherds, a few glass beads and a little fragmentary bronze, many tanged iron knives and projectile points and short spear blades as well as charcoal. 
Van Den Bergh and Luangaphay (2008) note the site comprises two groups of 33 sandstone jars sitting atop what is called Naluang hill, a low, flat-topped, foothill. They report two stone lids or discs at the site. Genovese (2015) provides same numbers of features and labels the site QS28. She notes that a pommel decorated disc mentioned by Colani is still extant.

Site 33 (Colani: Eight jars/Genovese: J33?)

It is difficult to be sure that the site labelled Site 33 in the SPJP report equates to the site known by Colani $(1935: 243)$ as "Eight Jars" near Ban Nam Ngum but the numbers and location seem to make this likely. Colani mentions the existence of a group of jars at the high point of a pass in the mountains. Four of the jars, fashioned from a quartz-rich sandstone, were standing while the other recumbent jars were broken. Colani conducted 'perfunctory' excavations around the jars finding ceramic sherds and bronze and iron fragments as well as tanged iron knives. The jars held no contents.

Site 33 is located near Ban Hok and San Phou Hok in Kham District. The account in the SPJP report indicates that it comprises four groups of jars, nine in total, on the lower foothills of a mountain. Some of the jars are unfinished and they feel that there must be a quarry nearby or perhaps that the site itself is a quarry. The fourth group (one jar) was discovered when vegetation was burned by the locals which may be why it was overlooked by Colani. Genovese (2015) has mapped a site in the same area as Site 33 and labelled it as J33 stating that it contains nine jars but provides no further information.

\section{Site 34 (Colani: n.d./Genovese: J29)}

This site was not known to Colani and named Site 34 by Van Den Bergh and Luangaphay (2008). The SPJP report locates it near the village of Ban Xang, Nam Oun in Kham District. The site comprises one group of four jars and one group of two or three jars located in a valley near the river. The limestone jars are noted to be fragmented. The site is recorded by Genovese (2015) who notes seven limestone jars but provides no further information and named it J29.

\section{Site 35 (Colani: n.d./Genovese: J30?)}

Site 35 is located near Ban Nathong, San Phou Kokhe in Kham District on the slope of a mountain (Van Den Bergh and Luangaphay, 2008). Two of the three sandstone jars are standing and the recumbent jar is in perfect condition. The site is not mentioned by Colani. Genovese (2015) states that there are three sandstone jars at this site which she labels as J30 and it is presumably the same as Site 35 . She provides no further detail on the site.

\section{Site 36 (Colani: n.d./Genovese:n.d.)}

This site is located close to a village called Ban Sai in Phoukout District on the lower slopes of a mountain and near a stream. According to the SPJP report the site comprises a group of three incomplete jars and it is interpreted as a transport site based on the lack of suitable rock source nearby (Fig. 35).

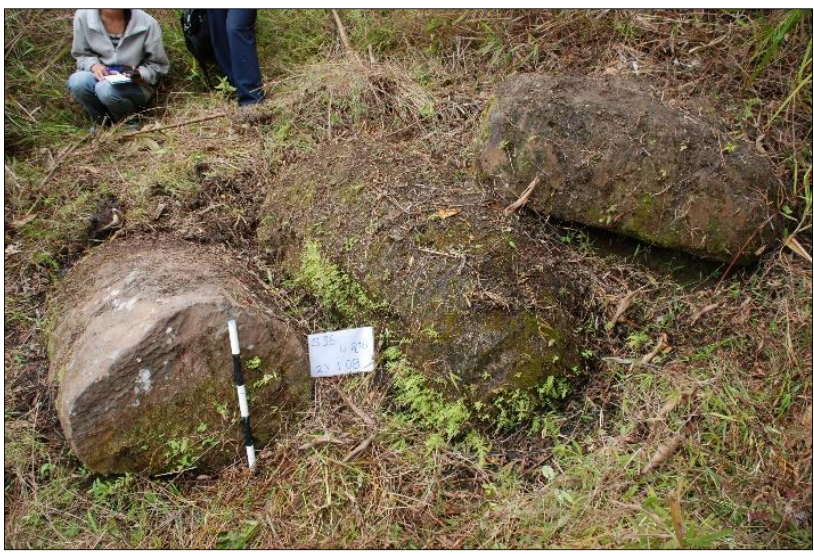

Figure 35. Unfinished stone jars at Site 36 (photo: SPJP).

\section{Site 37 (Colani: n.d./Genovese: J31)}

Van Den Bergh and Luangaphay (2008) place this site near Ban Sikhoun village in Paek District. It comprises a single, recumbent, sandstone jar on a lower hill slope (Fig. 36). Genovese (2015) has a site marked on a map that is in the vicinity which she labels as J31, similarly with a single jar.

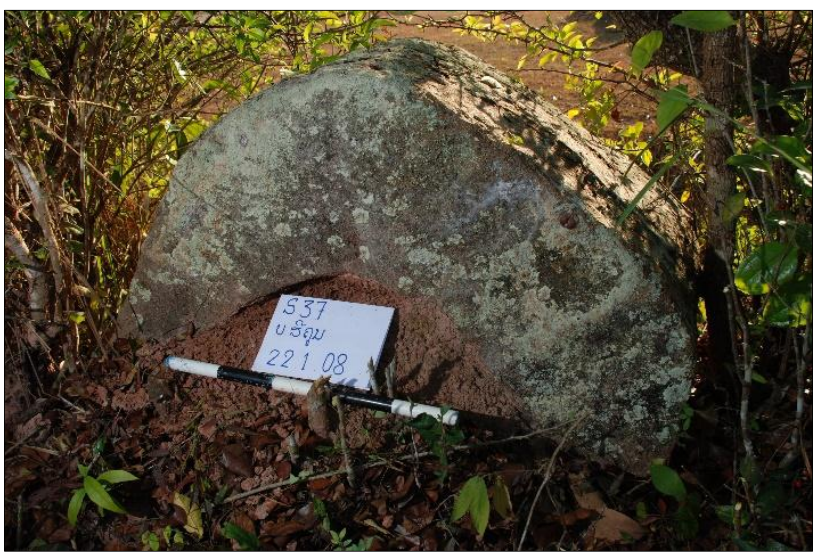

Figure 36. Stone jar at Site 37 (photo: SPJP).

Site 38 (Colani: n.d./Genovese: J32)

Three sandstone jars are found near the villages of Ban Phonekham and Ban Sikhoun in Paek District (Fig. 37). The jars lie in a flat upland area and all are broken. Genovese (2015) records a site which she labels as J32 in the same area but claims it has just two sandstone jars and provides no further detail.

Site 39 (Colani: n.d./Genovese:n.d.)

According to the SPJP report this site is located close to Ban Phonekham in Kham District, located on a small hill and hosts two groups of jars with four and seven jars each. The jars are fashioned from limestone and in very poor 
condition (Fig. 38). No site in this area is recorded by Colani or Genovese.

Site 40 (Colani: n.d./Genovese:n.d.)

Nine jars are recorded near the village of Ban Namthoum in Kham District which is located in a high pass between two mountain peaks. The main group of jars comprises eight megaliths, half of which are damaged. One jar resides in the village itself. The site recorded by Van Den Bergh and Luangaphay (2008) as Site 40 is not mentioned by Colani (1935) or Genovese (2015).

Site 41 (Colani: n.d./Genovese: QS34?)

This site comprises a single, poorly preserved, limestone jar located near the village of Ban Tha in Kham District and located on a hill (Fig. 39) (Van Den Bergh and Luangaphay, 2008). The site is not recorded by Colani (1935).

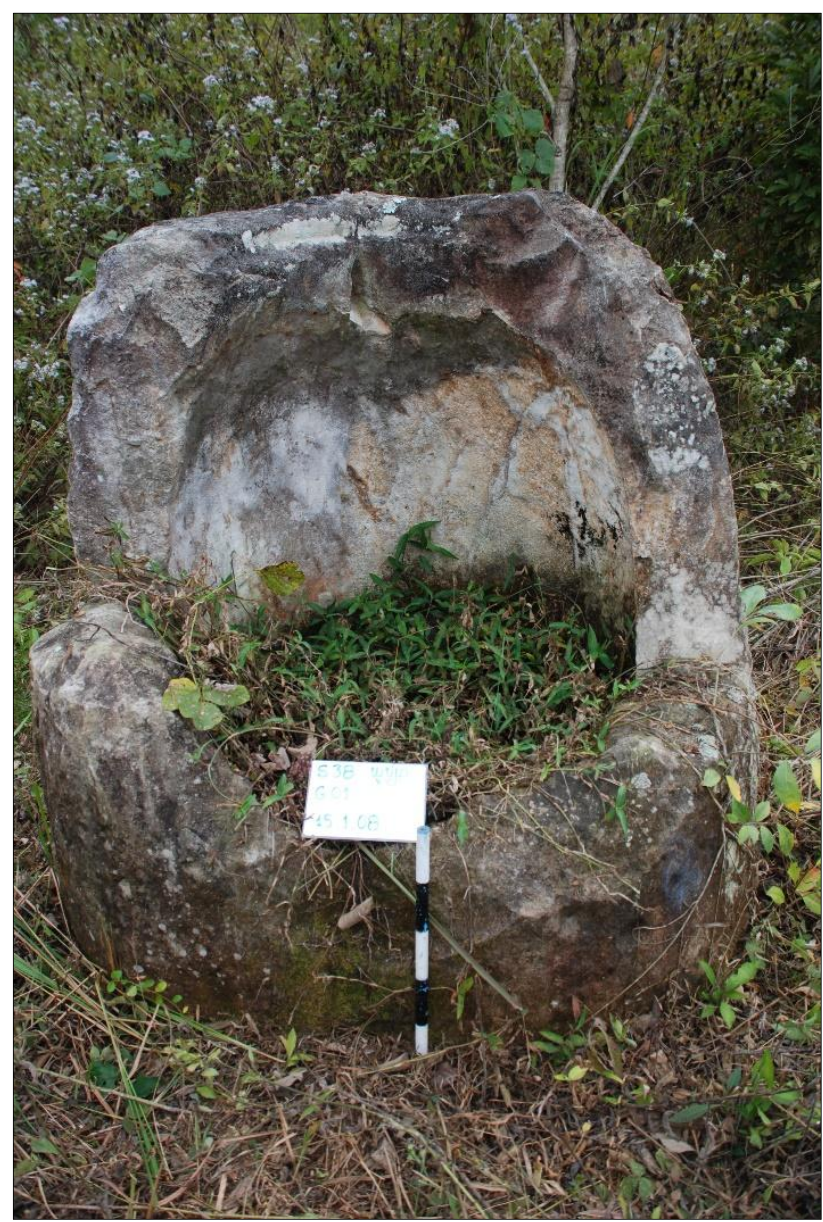

Figure 37. Stone jar at Site 38 (photo: SPJP).

The site labelled QS34 by Genovese (2015) is said to be located c. $14 \mathrm{~km}$ from Route 7 and $13 \mathrm{~km}$ from Ban Tha village in Kham District. It comprises one very fragmented limestone jar. Genovese $(2015: 173)$ notes that the site was visited by Dussault in 1912. In examining Genovese's map it appears that QS34 is located about $12 \mathrm{~km}$ west of Site 41 but probably relates to the same site.

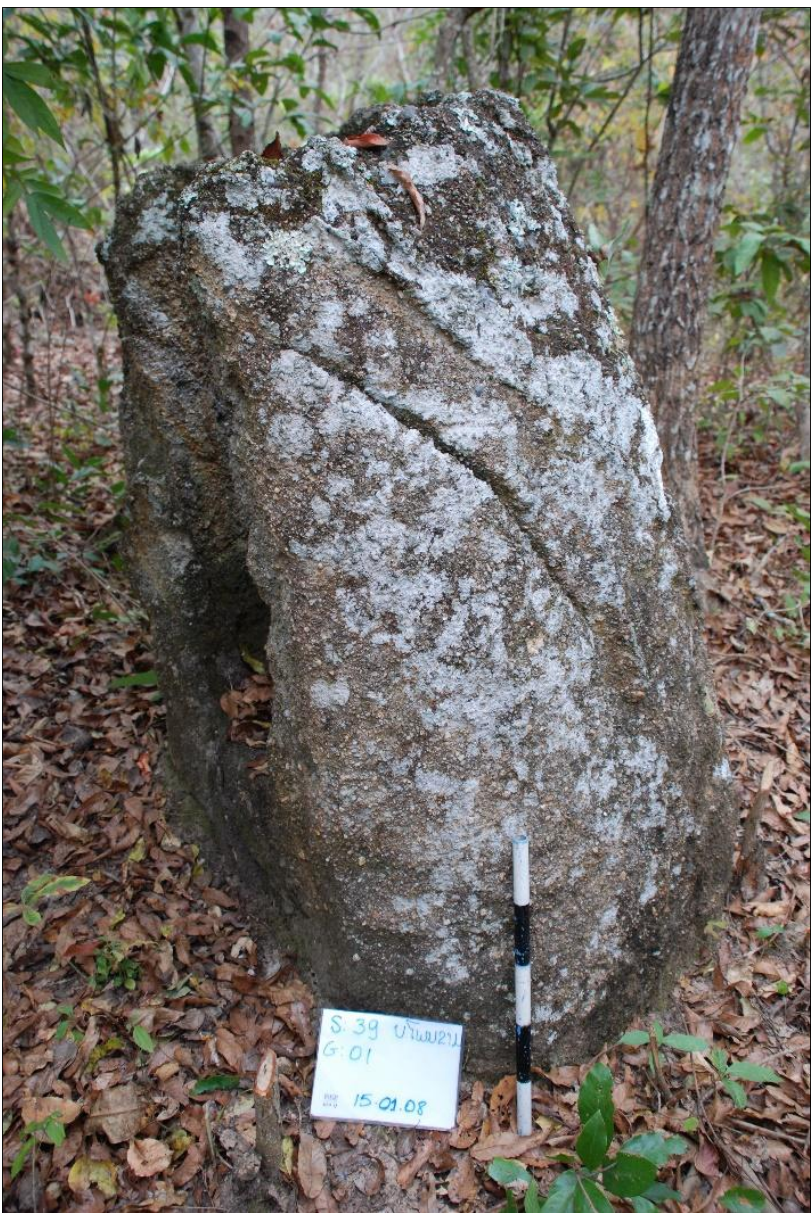

Figure 38. Stone jar at Site 39 (photo: SPJP).

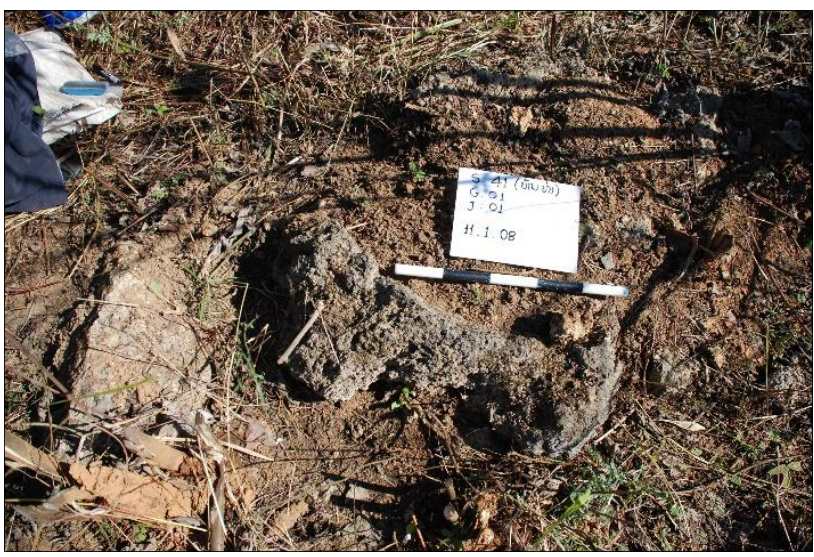

Figure 39. Eroded stone jar at Site 41 (photo: SPJP).

Site 42 (Colani: n.d./Genovese: QS35)

Located near the village of Ban Xang and Ban Phu Xang in Kham District, Site 42 comprises five jar groups totaling 90 jars. Groups 1, 2, 3, 4 and 5 have 32, 42, 12, one and three jars respectively. The jars are reported in the SPJP report to be of fine red sandstone (Fig. 40). Five discs are reported from the site as well, one of which has a stone loop on it (Fig. 41). It is suggested that the site is both a 
quarry and jar site as evidence of quarrying of the source rock is on site. Genovese (2015) calls this site QS35 but counts more jars, totalling 132. She also records some discs with pommels and trimmed blocks of stone which she believes indicates that the technique for carving was to shape the exterior of the jar in the first place and later carve the cavity.

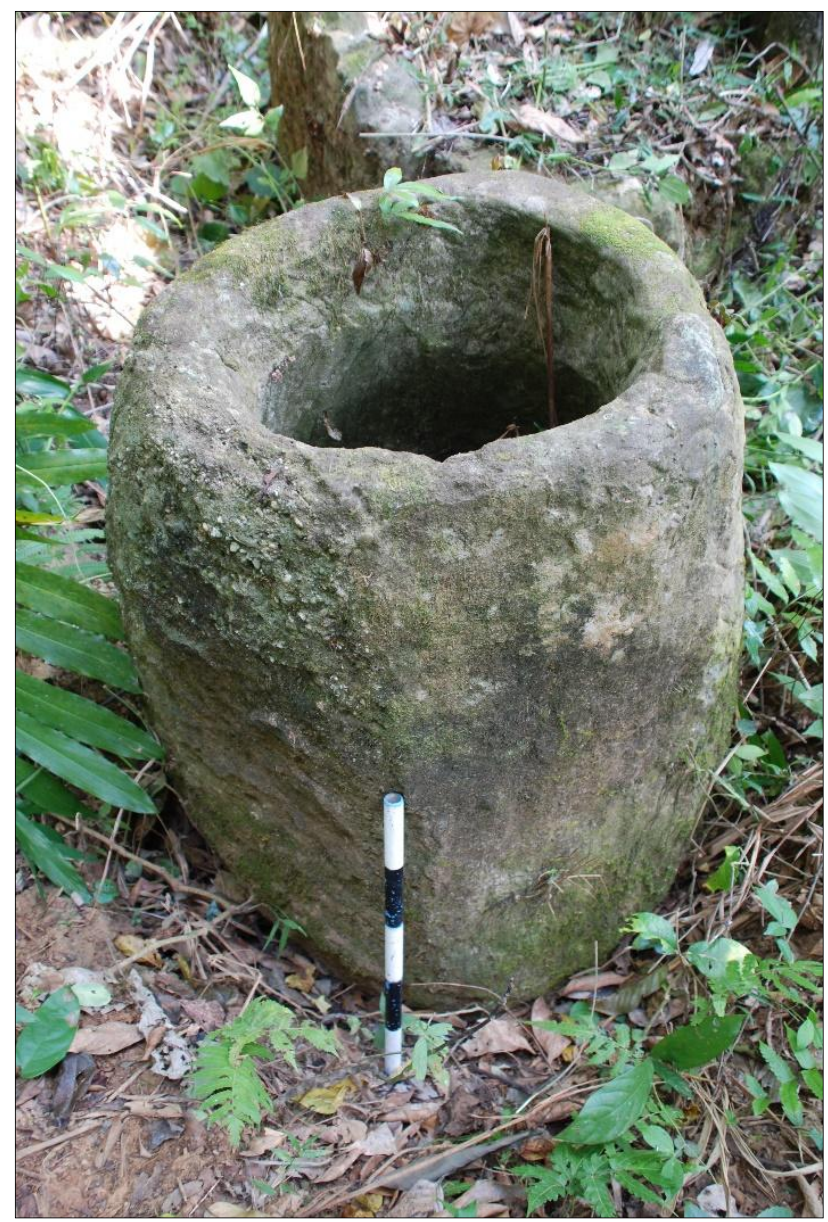

Figure 40. Stone jar at Site 42 (photo: SPJP).

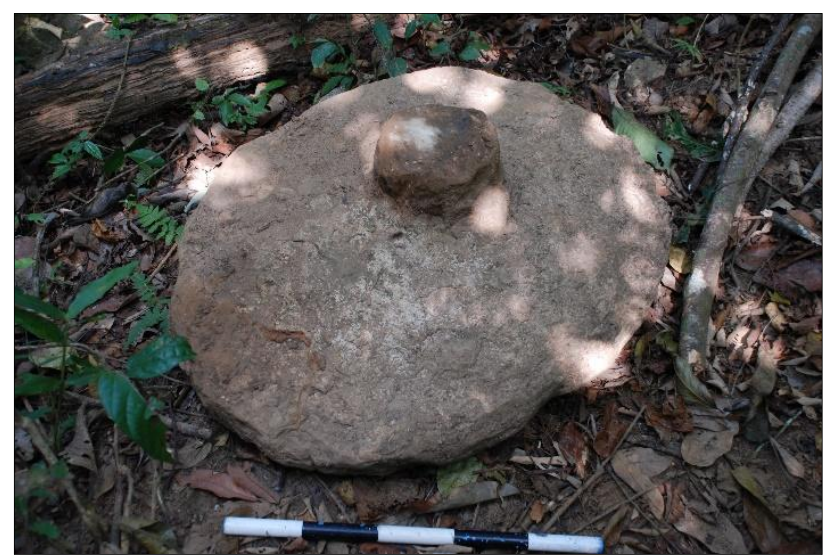

Figure 41. Disc at Site 42 (photo: SPJP).
Site 43 (Colani: n.d./Genovese: J36)

Site 43, home to 35 limestone jars, is listed in the SPJP report as being located in Paek District near Phakhom Phu Hai Hin. Genovese (2015) also records 35 jars at this site which she has labelled J36. Some of the jars, she notes, are 'dwarf' jars. Both parties describe damage to the jars, noting their use as chicken coops by local farmers who bored holes near the bases (Fig. 42).

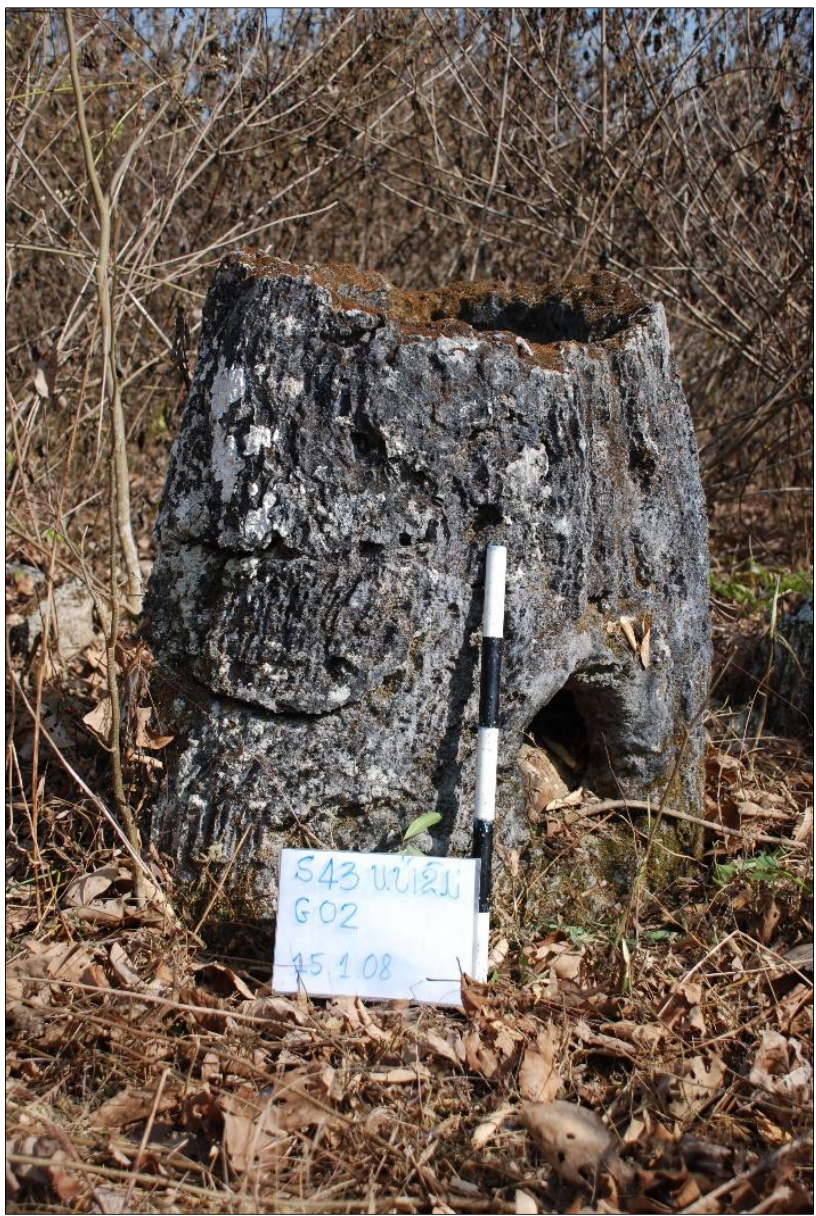

Figure 42. Stone jar at Site 43 (photo: J. Van Den Bergh).

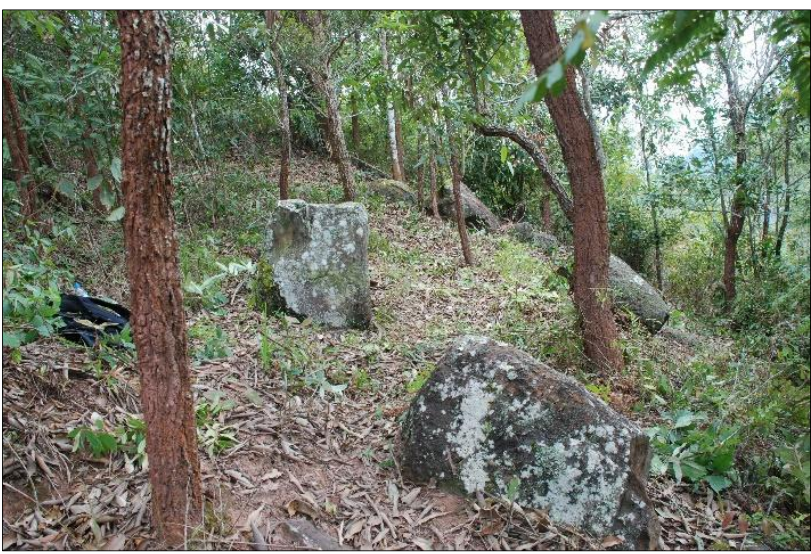

Figure 43. View of Site 44 (photo: SPJP). 
Site 44 (Colani: n.d./Genovese:n.d.)

Thirteen jars in two groups are located near Phu Namkhun and Sangniac Nong Paek in Paek District (Fig. 43). They are found on a steep slope in a mountainous setting and the site, in the opinion of Van Den Bergh and Luangaphay (2008), represents a quarry site at which excavation bays can still be seen where the fine-grained sandstone was removed. They note a large number of unfinished jars many displaying unintended breakages that occurred during manufacture.

\section{Site 45 (Colani: n.d./Genovese:n.d.)}

At Site 45, located near Ban Nasel and San Phou Huathum, Phoukout District, comprises six jars in one group (Fig. 44). According to the SPJP report the massive jars are located on a hill. No further detail is provided on this site.

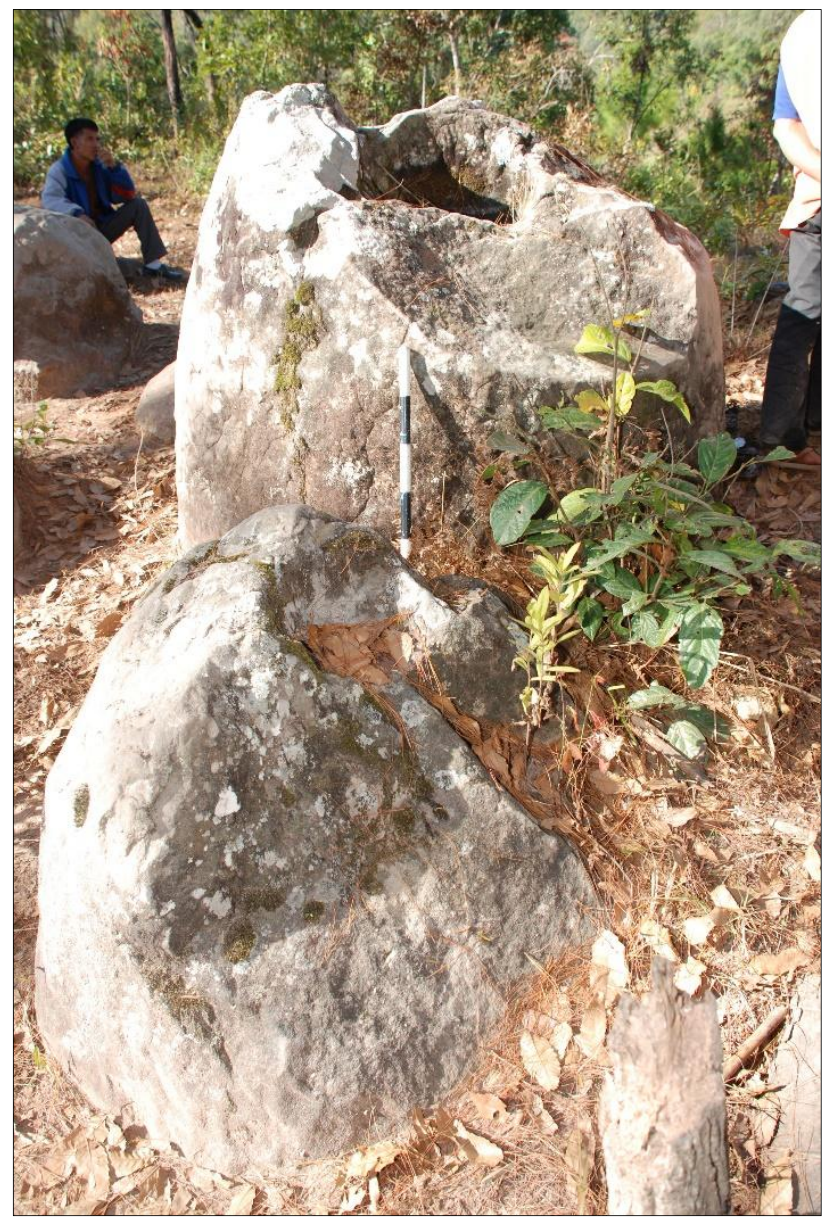

Figure 44. Stone jars at Site 45 (photo: SPJP).

Site 46 (Colani: n.d./Genovese:n.d.)

Two jars close together make up Site 46 near Ban Ang, Phu Nasan in Phoukout District (Van Den Bergh and Luangaphay, 2008). The massive sandstone jars are recumbent with small apertures (Fig. 45). No further detail is provided regarding this site and it is not recorded by either Genovese or Colani.

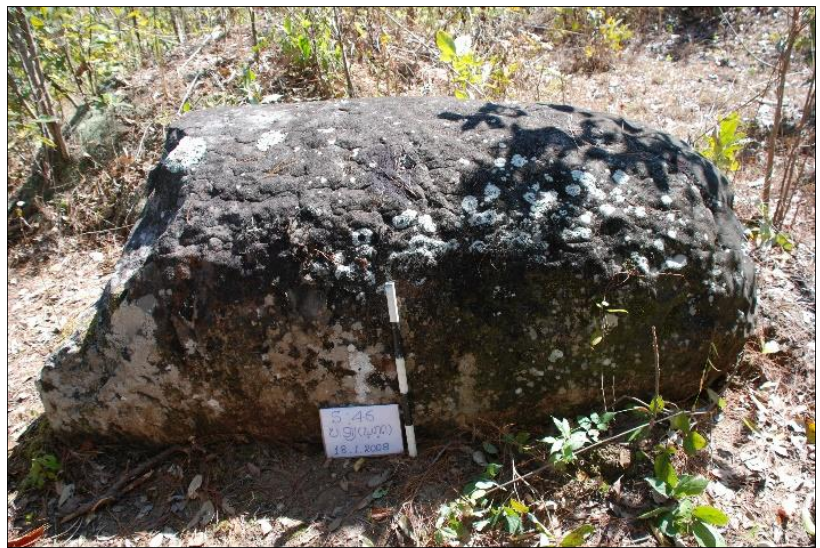

Figure 45. Stone jar at Site 46 (photo: SPJP).

Site 47 (Colani: n.d./Genovese:n.d.)

Site 47 is found near Ban Thalin, Khoune District. The site is recorded in the SPJP report as being located on a lower mountain slope where 85 mostly fragmented jars were recorded in two groups, one group with just two jars (Fig. 46). One disc is recorded.

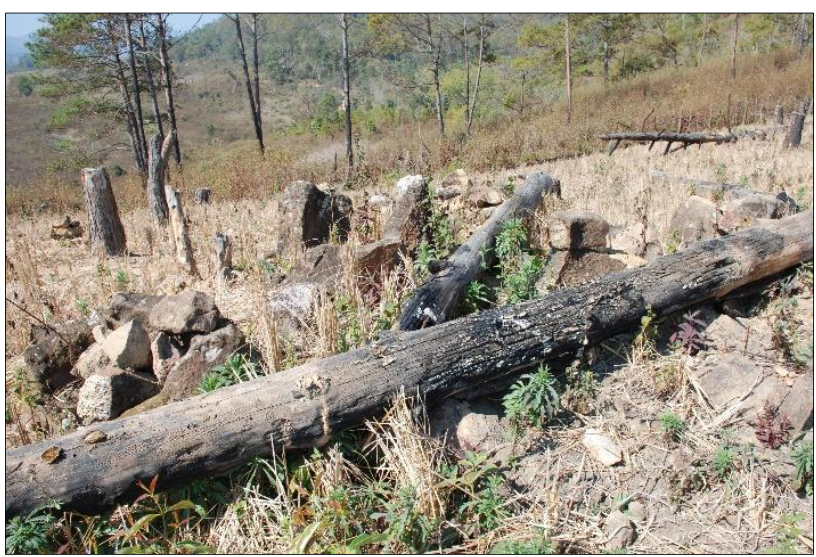

Figure 46. View of Site 47 (photo: J. Van Den Bergh).

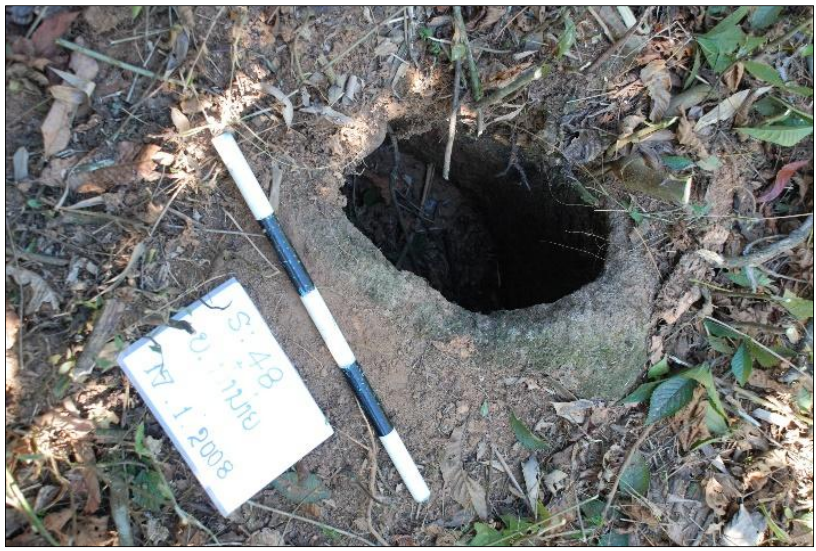

Figure 47. Buried jar at Site 48 (photo: SPJP). 
Site 48 (Colani: Song Méng Group/Genovese: J38)

Colani (1935) documented groups of jars near a place called Song Méng about $20 \mathrm{~km}$ from what is now Muang Khoun (then Xieng Khouang, the provincial capital). She recorded seven jars both intact and fragmented and five more some $50 \mathrm{~m}$ away. She thought it possible that further jars may have been buried in between these two groups as most of the jars at the site were buried up to their rims. Colani noted the presence of two large 'lids' or possibly discs. The jars held only a few glass beads the colour of terracotta. The excavations she undertook around the jars revealed ceramic sherds, bronze and iron fragments and some glass beads as well as ceramic sherds. The jars she investigated sat atop beds of granite fragments.

Colani visited the site again in 1940 and discovered another field of jars nearby. She excavated and discovered several granite discs with zoomorphic designs carved in the round (Colani, 1940). The account of the site in the SPJP report indicates that the jars are of limestone and comprise three groups located on two hills. The jars in group one appear smaller and are buried (Fig. 47). The report notes 17 jars to be present near the village of Ban Nam Nai in Khoune District. Genovese (2015) calls this site J38 and relates it to Song Méng stating that it is home to 17 limestone jars. She reports that she was unable to locate the granite discs recorded during Colani's 1940 work.

Site 49 (Colani: n.d./Genovese: QS39)

According to the SPJP report there are 61 jars at Site 49 which is surrounded by a few granite outcrops near the village of Ban Phiang Na Phoi in Khoune District (Fig. 48). Genovese (2015) named this site QS39 and accounts the same number of jars noting also that they are small in size and mostly buried.

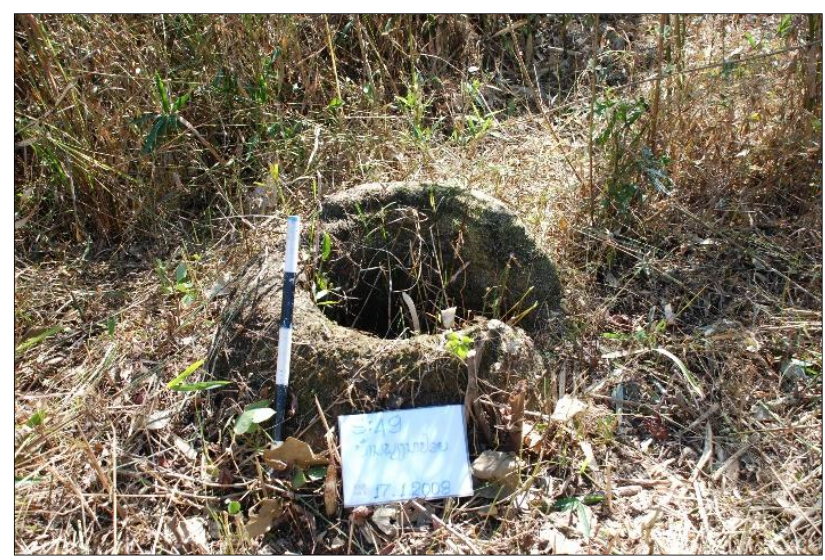

Figure 48. Stone jar at Site 49 (photo: SPJP).

Site 50 (Colani: n.d./Genovese:n.d.)

According to the SPJP report this site is located c. $200 \mathrm{~m}$ from the village of Ban Huayhok in Khoune District and comprises 23 sandstone jars of fine quality red stone (Fig.
49 and 50). The site is found on a mountain ridge in a circumscribed area. Some damage to the jars was reported as the local ethnic group had been using fragments of the jars to cover contemporary graves (Van Den Bergh and Luangaphay, 2008).

\section{Site 51 (Colani: n.d./Genovese: J40)}

Site 51 is found about two km from Ban Sang Luang and contains 14 weathered granodiorite jars and two. According to Van Den Bergh and Luangaphay (2008) the jars may have originally been buried to their rims but the landscape appears to have altered, exposing the jars (Fig. 51 and 52). Genovese (2015) documents this site as J40 and counted 16 small jars, some of which were buried. She also noted that, during her 2011 visit, some of the jars appear to have been exposed by excavations.

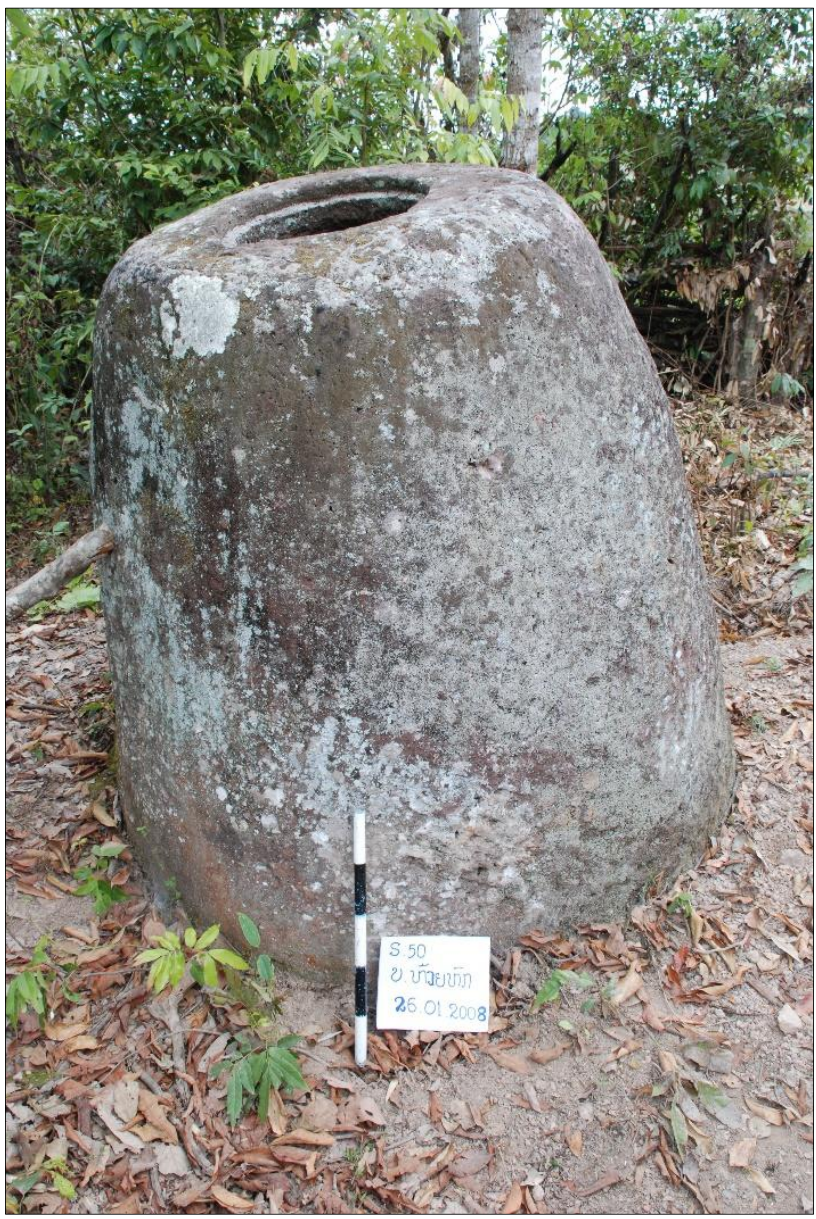

Figure 49. Stone jar at Site 50 (photo: SPJP).

Site 52 (Colani: n.d./Genovese: J41)

This site is located atop a mountain not far from the village of Ban Phakeo in Paek District. Most of the jars occupy a saddle between two higher peaks. The site was unknown to Colani but was documented in 2001 by Van Den Bergh and Luangaphay (2008) who labelled it Site 52. They documented four groups and counted nearly 400 jars (Fig. 53). 
Genovese (2015) labels this site as J41. She counted 371 jars and 96 discs at the site.

Recent research at Site 52 by the authors has identified two further groups of jars increasing the total to 420 sandstone jars and 182 discs/lids. Group 1 comprises 115 jars and 44 lids or discs, Group 2, 82 jars and 52 lids/discs, Group 3, 195 jars and 70 lids or discs, Group 4, 24 jars and 15 lids or discs and Group 5 and 6, previously undocumented contained four and one jars respectively and Group 5 had one lid.

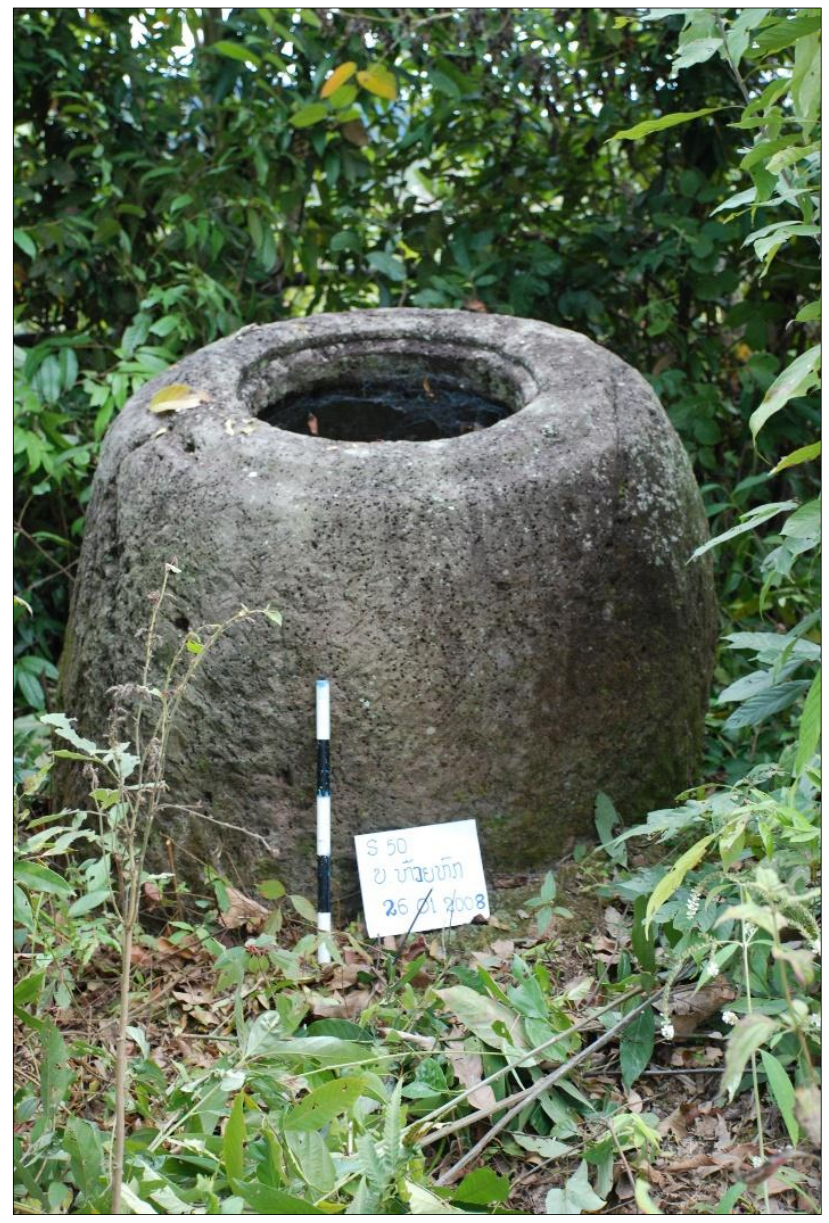

Figure 50. Stone jar at Site 50 (photo: SPJP).

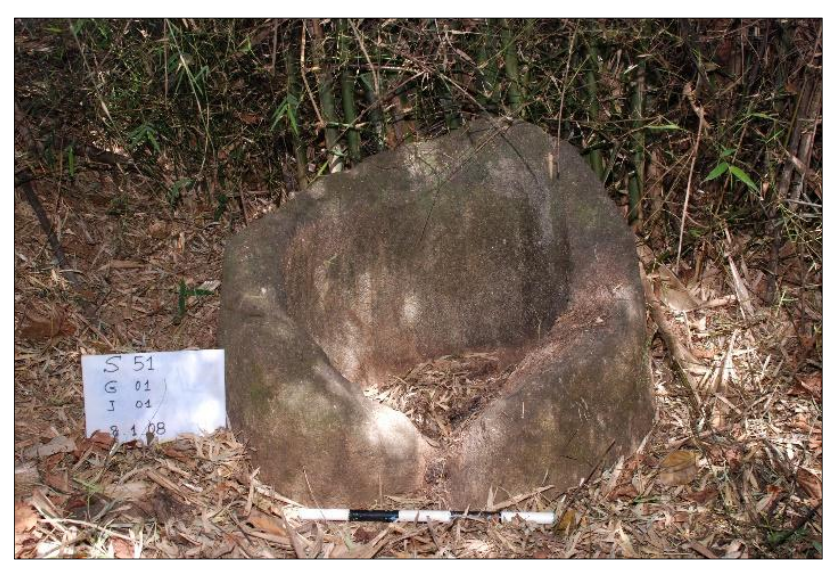

Figure 51. Stone jar at Site 51 (photo: SPJP).

Site 53 (Colani: n.d./Genovese:n.d.)

Site 53 is located in Phoukout District, near the village of San Phu Niathau. A single sandstone jar, surrounded by boulders is located on a mountain ridge (about $800 \mathrm{~m}$ from Site 30) according to the SPJP report.

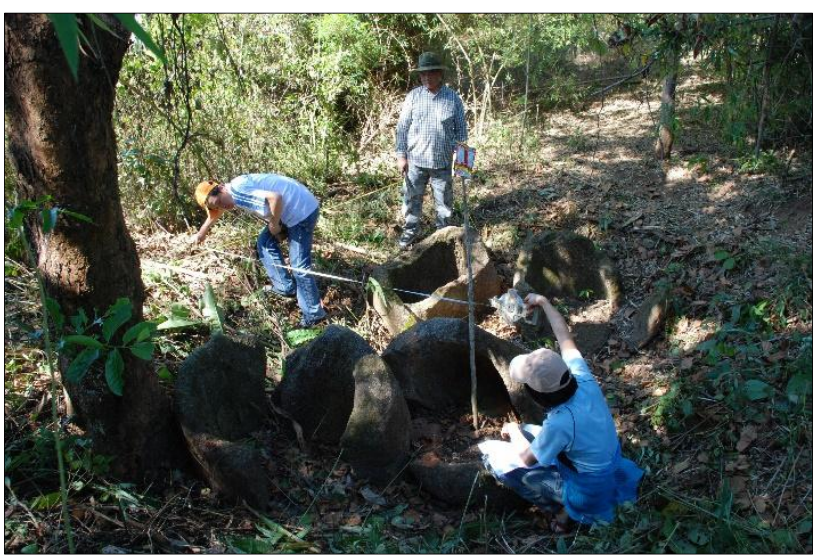

Figure 52. Documenting stone jars at Site 51 (photo: SPJP).

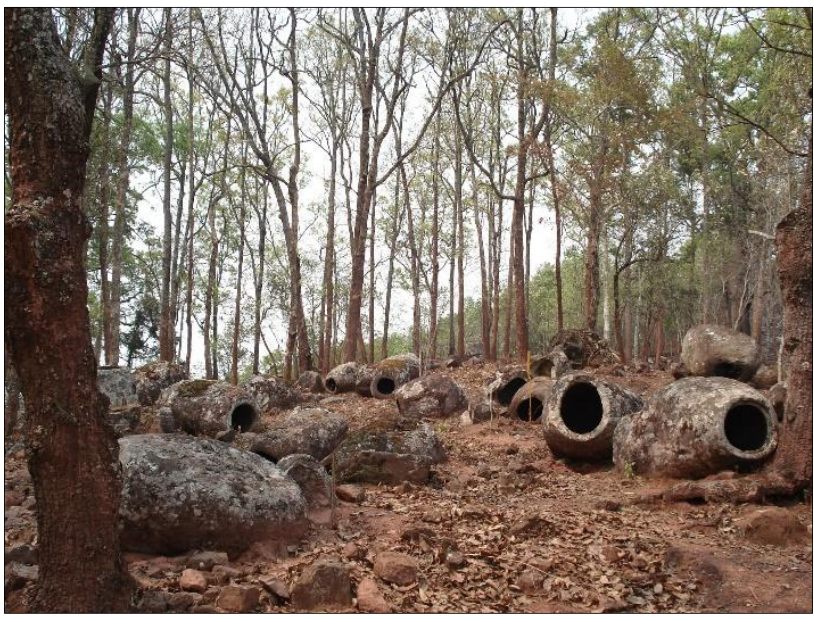

Figure 53. View of Group 1 at Site 52 (photo: SPJP).

Site 54 (Colani: n.d./Genovese: Ban Vangkham)

Site 54, comprising a single sandstone jar, is located in Phukout District near Ban Vangkham. Van Den Bergh and Luangaphay (2008) report the jar has been converted to an animal feed trough and has been badly damaged. According to Genovese (2015) Ban Vangkham is an unspecified distance from the village of Khum Vangkham, a five-hour trek from Genovese's site QS42. Genovese (2015) reports the site is home to a single sandstone jar.

Site 55 (Colani: n.d./Genovese: QS42)

Two incomplete sandstone jars were documented by Van Den Bergh and Luangaphay (2008) near Ban Chomsy in Phukout District. The jars are located on a low hill near a 
river. Genovese (2015) dubs this site QS42 and also reports two jars stating that evidence for in situ carving is apparent. She reports both jars to be recumbent.

Site 56 (Colani: n.d./Genovese:n.d.)

This site is not mentioned by either Colani or Genovese. It is located by Van Den Bergh and Luangaphay (2008) near Phu Biac village in Kham District and boasts just one sandstone jar sitting on a rise (Fig. 54).

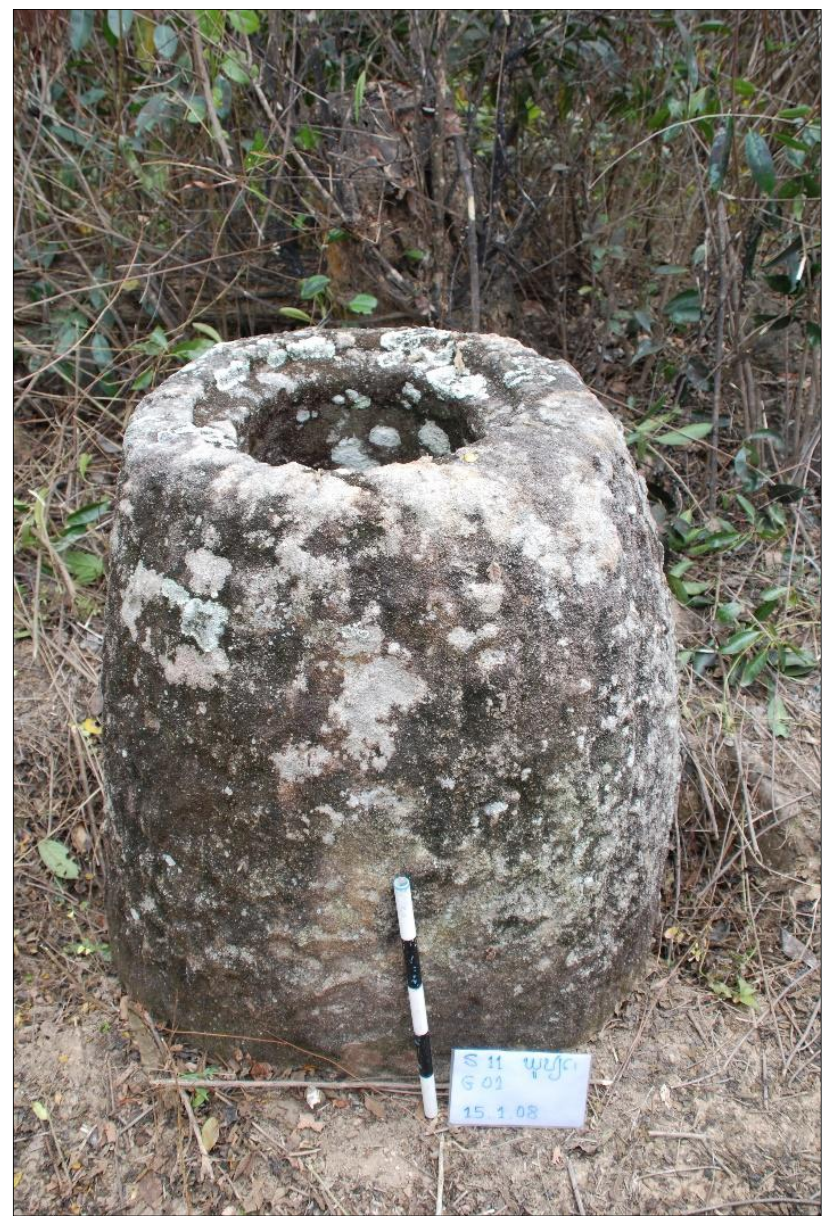

Figure 54. Stone jar at Site 56 (photo: J. Van Den Bergh).

\section{Site 57 (Colani: n.d./Genovese:n.d.)}

Near the village of Ban Phiangxai in Kham District, three groups of conglomerate jars are described in the SPJP report. The groups comprise three, five and one jar respectively. The nine jars are located on a mountain ridge but they are reportedly in very poor condition and badly fragmented.

Site 58 (Colani: n.d./Genovese:n.d.)

Near the village of Ban Phiangxai in Kham District, three groups of conglomerate jars are noted in the SPJP report. The groups comprise three, five and one jar respectively. The nine jars are located on a mountain ridge but they are reportedly in very poor condition and badly fragmented. Neither Colani or Genovese mention the site.

\section{Site 59 (Colani: n.d./Genovese:Ban Naséo)}

Site 59, is located very near the village of Ban Nasel in Phoukout District (Van Den Bergh and Luangaphay, 2008). There is a single sandstone jar and two stones at the location which is about $800 \mathrm{~m}$ east of Site 45 . There is no mention of this site either by Colani or Genovese. It is possible that the site Genovese (2015) refers to as Ban Naséo relates to this site as Genovese credits one jar to this site.

\subsection{SITES NOT DOCUMENTED IN THE SPJP REPORT}

Several sites have been reported, both by Colani (Fig. 2) and Genovese (Fig. 4), which do not appear in the list of sites compiled by Van Den Bergh and Luangaphay (2008) in the SPJP report or are located in the province of Luang Prabang. A list of these sites and sites detailed by Genovese (2015) with brief descriptions of each is provided below. There is a possibility that some of these locations are duplicates but to the best of our understanding they represent different sites from those listed in the SPJP report.

\section{Genovese: J27}

Genovese's (2015:164) map places this site in Phukout District quite close to Site 31 but, again, the number of jars recorded does not match that provided by Van Den Bergh and Luangaphay (2008) for this location. Genovese records four sandstone jars (Site 31 is thought to have nine jars) and three discs. Genovese's J27 has jars with apertures at each end and are over $2 \mathrm{~m}$ in length, a trait found in jars at Site 31 . She also mentions a dwarf jar nestled next to one of these large jars and this is described by Colani (1935) for Ban Si which is likely Site 31 according to Van Den Bergh and Luangaphay (2008).

Genovese: J45 /Colani: Ban Ngam Num?

Genovese (2015) plots a site in Paek District she names as J45 but provides no further information other than to say there are six sandstone jars at the location. The site may correspond to Colani's (1935:239) Ban Nam Ngum site where she recorded eight sandstone jars.

\section{Genovese: J46}

Site J46, so named by Genovese (2015), is not recorded by Colani (1935) and was not included in the survey by Van Den Bergh and Luangaphay (2008). The site, in Kham District, is located on the banks of the Nam Mat River and comprises six fragmentary sandstone jars.

\section{Genovese: J48}

Genovese documents a single, broken, jar formed from conglomerate stone at this site in Kham District. She notes it bears a recessed inner rim and was $1.5 \mathrm{~m}$ high. Villagers informed her that three other jars were nearby until recently (Genovese 2015:174). The site is not documented elsewhere. 
Genovese: J50

The location given on the map for J50 by Genovese (2015:166) is near that for a site named 'The Eleven Jars' by Colani (1935), however, according to Genovese's account the two jars and two discs at the site were moved to this location prior to the construction of the Nam Ngum 5 Hydropower dam. The jars, relocated from an area slightly to the south of their current position, are now located at Ban Nanan, Phou Khoun District, Luang Praban Province (Genovese 2015:168). According to a report by the DoH (Khamphoumy, 2013) the jars at Ban Nanan were excavated in 2011 and many stone jars were found and some 'lids' with human figures engraved on them. Finds included beads, pottery and stone jar and lid fragments. An interesting statue in the round was discovered at this site. Although crudely fashioned it appears to be an individual supporting his or her head with one hand.

\section{Genovese: J51/Colani:San Hin Oume}

J51, registered by Genovese (2015:70), is thought by her to be the same site named San Hin Oume by Colani (1935) and based on photographs by each this can be confirmed. The former author describes a site with 21 jars and 21 discs, all of sandstone. Today the local toponym is Phu Da Pho (Genovese 2015:70) and the jars there are about 120 $\mathrm{cm}$ tall with shallow cavities.

Colani's description of San Hin Oume places the site in current-day Luang Prabang Province. She provided descriptive details regarding the location but no coordinates for the site, stating that it is about $25 \mathrm{~km}$ from a site she called Thao Kham. Colani (1935:221) describes the site as sitting on a spur, aligned north south in a "complicated jumble of mountains." The site revealed sandstone jars, discs and boulders strewn over an area measuring $12 \times 8$ $\mathrm{m}$ and she notes the jars and discs were worked from the stone present at the site (Colani 1935:125, 222). The discs at the site are described by Colani as resembling 'mushrooms' and these were only noted at this site and at 'The Eleven Jars' site (see below). She describes these as discs with three parts: a top; a truncated cone; and a foot, in truncated cone form or cylindrical (Colani 1935:170). On some of these were animal forms, carved in relief. Colani's excavations uncovered polished stone tools, globular ceramic vessels placed mouth-to-mouth, decorated and undecorated potsherds, iron knives and charcoal.

\section{Genovese: J52}

The location of Genovese's J52, in Phou Khoun District, Luang Prabang Province, is c. $8 \mathrm{~km}$ from the village of Ban Nanan and Genovese $(2015: 168)$ states is likely to correspond to one of the sites surveyed by Colani. The site is known locally as Nam Phat and contains 19 sandstone jars. The altitude is placed a $1110 \mathrm{~m}$ asl and is less than one $\mathrm{km}$ from J50.

\section{Genovese: Q10}

Genovese (2015) provides no coordinates for the location of this site and states that it contains no jars. Using a map overlay, however, it appears that the site may be erroneously placed as it sits within the jar groups at Site 52 itself. She states that this is a quarry for QS11, J41 (Site 52) and QS44 (Site 10). It is likely that this site represents one of the quarry or transport sites identified by Van Den Bergh and Luangaphay (2008).

\section{Genovese: QS47}

QS 47 comprises a single limestone jar at a rock face in Kham District but there may have been at least two more there until recently (Genovese 2015:188). Genovese believes that this site is located near a site documented by Dussault in 1912 called San Tiau (see below). QS47 is reported to be located on a hillock near Phou Huay Xang Kaen village.

\section{Genovese: QS49}

This site is described as being located in Ban Naho in Khoune District. Genovese (2015:157) notes the site was not included in the Lao government database she had access to and she discovered nine granite jars near the village of Hoy Phu Mee at an altitude of $1130 \mathrm{~m}$. She notes that there are a variety of different rim styles represented here.

\subsection{FURTHER UNCONFIRMED SITES}

Several megalithic jar sites documented by Colani (though not revisited) and several sites recorded by Van Den Bergh and Luangaphay (2008) and Genovese 2015 (but not documented or geo-located) are listed below. Further survey is required to accurately locate these sites and confirm the presence of archaeological remains in their vicinity.

\section{Colani: The Eleven Jars}

Colani (1935) mentions a site she dubbed 'The Eleven Jars' about a day's march from San Hin Oume. The jars are said to be located a c. $900 \mathrm{~m}$ asl near a village, then called Vang Pha Houane, populated by Kha people. Colani (1935:226) provides details of each of the jars at the site and describes a roughed-out representation of a quadruped in stone. Colani did some 'perfunctory' excavation but found nothing in the ground or in the jars.

\section{Colani: Kéo Tane}

Colani (1935: Map IX) plots a site called Kéo Tane in a mountainous region about $11 \mathrm{~km}$ from a place then known as Xieng Dan, east of a village called Ban Houai Thouak. The site comprises three robust jars, upright, and two complete discs and a fragment of a third. The two complete discs are decorated with a recumbent mammal carved in the round. The jars are recorded as having been between $110-140 \mathrm{~cm}$ in height, all made of sandstone. Colani's (1935:fig.187) digging around the jars revealed two ground stone axes.

\section{Colani: Sud de Keotane}

To the south of Kéo Tane, Colani (1935) documented a group of three sandstone jars, two of which were lying down and two buried discs, the latter were decorated with 
a mammal carved in the round. A third undecorated disc was also encountered (Colani 1935:218). The standing jar was reported to be $130 \mathrm{~cm}$ in height and is located near a large boulder that Colani describes as resembling a human face. It appears that there were some roughed-out jars at the sites as well.

Colani excavated around the jars and found a worked piece of shale, a rectangular pendant, a ceramic vessel capped with a large stone, ceramic sherds and a bronze bangle as well as some charcoal. Beneath a large flat stone she found a pendant and a ceramic vessel.

Colani: Circular path linking fields of jars

Colani (1935:219) makes mention of another field of jars, again, south of Kéo Tane which she labels as the 'Circular path linking fields of jars'. In this location she describes a 'small field of jars with two statues of mammals and a stone carved with lines. Nearby there is a cylindrical stone decorated at the top with a small disc and two small stones decorated with poorly formed quadrupeds. She reports that she did not have time to investigate the whole area but locals informed her that there were no further points of interest in the vicinity.

\section{Colani: Est de Keo Tane}

To the east of Kéo Tane, Colani (1935:219) notes a field of jars and discs and other worked stones. She does not provide a detailed account of the site but her plates show what she describes as a column (c. $65 \mathrm{~cm}$ in height), a discoidal button, a block with a quadruped carved upon it and another, similar, both in the round and what appear to be jar rough-outs. Her excavations at this location did not reveal any artefacts.

\section{Colani: Phuo Suong}

Although mentioned in her 1935 publication, Colani did not visit the site named Pou Soung (1935:257) but relies on a report from her sister, Mlle E. Colani. She reports the site is located five $\mathrm{km}$ east-north-east of Ban $\mathrm{Na}$ Séo at around $1320 \mathrm{~m}$ asl. There were three groups of jars and burial stones reported but not detailed. Genovese (2015:58) reports visiting a site of the same name stating that there are 38 jars there.

\section{Colani: Sop Nam Miang}

According to Colani (1935:224) Sop Nam Miang is a jar site located near the Eleven Jars, c. three kilometres southeast of a village called Ban Houa Ting where two jars are located. The largest jar is $130 \mathrm{~cm}$ tall and had a partially buried 'mushroom' disc nearby. No information on the second jar is provided. Also, near the large jar were six boulders of quartz-rich sandstone. Excavations revealed no artefacts.

\section{Colani: Unnamed Site}

Two jars are located by Colani (1935:257) as being placed somewhere between Ban Si and Ban Na Séo. She writes that each is on a rise, separated by a track. The jar to the west is cracked in half. No further information is provided regarding this site.

\section{Colani: San Tiau}

The site of San Tiau is mentioned by Colani as being located near a Hmong (Méo) village of the same name. Colani $(1935 \mathrm{v} 1: 124,125)$ mentions that the site was noted by Léon Dussault in 1912 and states that it comprises limestone jars. She did not visit San Tiau and it has not been documented since Dussault was there but it has been mentioned by former US Central Intelligence Agency (CIA) operatives who were based at a secret air base near the site known as Lima Site 2 in the 1960s (Castle pers. comm.). These reports indicate that, not far from the CIA airstrip, was a group of jars known locally as San Tiau. Genovese (2015) states that the site is located near the site labelled by her as QS47 (Genovese, 2014a:40).

\section{Colani: San Kama}

San Kama is rather a mythical site, at least it is known only through a local informant of Colani's, a "canton official". He reported that there was a field of 1000 jars at a place bearing this name located about $20 \mathrm{~km}$ from Thao Kham, a field of stones. Colani provides no direction from Thao Kham and she never visited the site and of the two scouts she sent out only one returned with a badly swollen neck and she was forbidden from interviewing him and so had to give up on locating this site (Colani 1935:8). Later, Colani did travel to the supposed location of San Kama but did not find any jars there. Similar accounts of huge jar site(s) between Phoukout and Phou Khoun districts were recounted by military personnel and villagers to Safeguarding the Plain of Jars team in 2003. The sites were reported to be remote and no attempt was made to visit as likely located outside the survey area in Luang Prabang.

\section{Genovese: Ban Phan}

Genovese (2015) notes the existence of a site in Paek District called Ban Phan at which there are an unknown number of sandstone jars. She offers no further information aside from rough geographical coordinates.

\section{Genovese: Pho Tsa Nghem}

Genovese (2015) offers some geographical coordinates for a site called Pho Tsa Nghem in Paek or Khoune Districts which is reported to have jars but the number is unknown although she quotes informants as saying it is a 'large deposit' of several dozens of either sandstone or granite jars. The site is near Genovese's Q18 (Site 18).

\section{Genovese: Ban Phuong}

General geographic coordinates are provided for this site in Khoune District which is reported to have ten granite jars. 
Genovese: Ban Khek

Ban Khek is reported to be in Khoune District and some general geographic coordinates are given but the number of jars and material they are made from is unknown.

\section{Genovese: Ban Sop}

Genovese (2015:46) states that a site called Ban Sop was first found by Raquez (1902). According to Genovese, Raquez travelled through Luang Prabang to Xieng Khouang and believes this site may be located to the northwest of the site she calls J26 (Site 27).

Genovese: Ban Sopma

Ban Sopma is within Kham district and comprises 12 jars. Genovese (2015:143) reports the site is accessible from Site 20 .

\section{Genovese: Phou Naséo}

Phou Naséo is mentioned once by Genovese (2015:121). She states that this site in Phoukout district is home to seven jars buried to their rims. The jars have a reported diametre of $20-30 \mathrm{~cm}$. The location of the site is unknown.

Van Den Bergh and Luangaphay (2008) note that there are a further 26 sites with stone jars in Xieng Khouang Province but no information other than the name of the village nearby these sites is provided and these remain undocumented at time of publication.

\subsection{RECENTLY DISCOVERED SITES}

In 2011 the Department of Heritage (DoH) produced an internal report stating that a new jar site had been discovered in Phu Koun district.

\section{Ban Chim}

In 2012 site of Ban Chim in Phu Koun District, Luangprabang was excavated by staff from the DoH in February 2012. The jars at Ban Chim were deeply buried to the rims. The jars were excavated and moved to a higher elevation as the area was scheduled for inundation as part of the Num Ngeum 5 Hydropower project. The unpublished internal report (Khamphoumy, 2013) makes no mention of the numbers of jars found at the site.

During field work in 2017 by the Plain of Jars Archaeological Project at Site 52 near Ban Phakeo several new sites were documented. These include what are either quarry or transport sites as most comprised unfinished jars. The sites were discovered late in the field season and there was little time to properly document them although the team recovered as much information as was possible. The sites were labelled with ' $Q$ ' numbers awaiting assignment of official site numbers by the Department of Heritage under the Ministry of Interior, Culture and Tourism of the Lao government.
Site $52 \mathrm{Q} 1$

Q1 is a possible quarry site comprising 21 jars in various states of completion and 16 boulders. This site is c. $900 \mathrm{~m}$ south of Group 3 at Site 52 (Fig. 55).

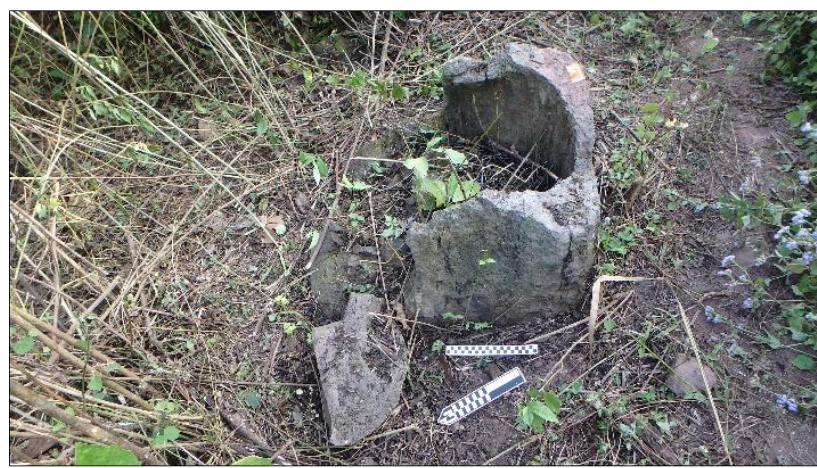

Figure 55. Broken incomplete jar at Q1 (photo PoJAP).

\section{Site $52 \mathrm{Q} 2$}

Q2 a quarry or transport site with more than 20 jars and roughs. The site is c. $1.2 \mathrm{~km}$ southeast of Group 3 at Site 52. The jar roughs at this site are rather widely dispersed. Two fragmented jar rough-outs are located at the bottom of a steep slope in a field cleared for swidden agriculture and a third jar is mostly intact with evidence of the beginnings of a cavity and some chisel marks on the body. These jar roughs are a pinkish-brown sandstone, quite different, visually, from the stone used for the jars at Site 52 (Fig. 56).

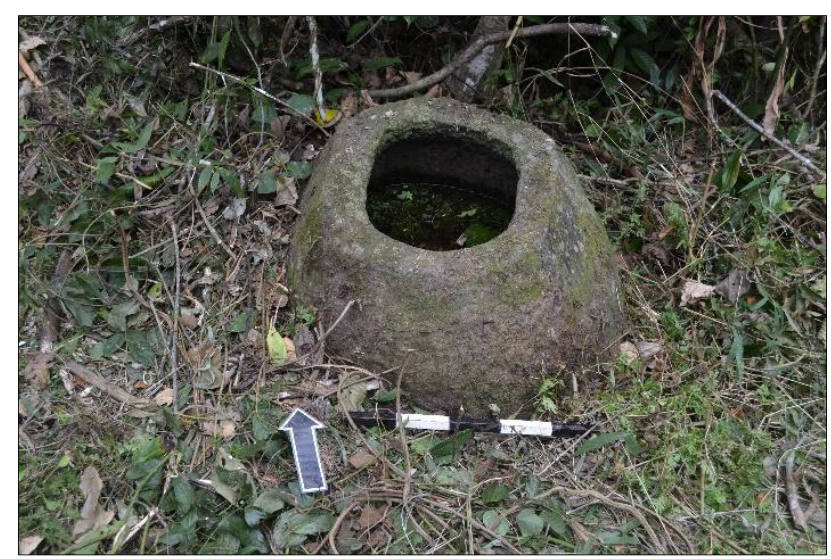

Figure 56. Broken incomplete jar at Q2 (photo PoJAP).

Ten to $15 \mathrm{~m}$ away from these three jar rough-outs there is a small stream. The stream gully contains several more jar rough-outs (possibly four). Most of these objects are no more than generally shaped but one has the beginnings of a cavity c. $10 \mathrm{~cm}$ deep. To the west of the stream there are two more jar rough-outs, one lies in the steep bank next to the stream. To the south of the jar rough-outs found in the gully 14 further jar rough-outs were counted. This is an area where two streams converge. Some of these objects appear to be only just begun to be formed into jars but one 
is nearly complete (the cavity is $\mathrm{c} .50 \mathrm{~cm}$ deep and the exterior well finished) and another has the beginnings of a cavity but appears to have been abandoned when the stone split.

\section{Site 52 Q3}

This possible quarry is located on a steep slope atop a mountain ridge with more than 23 jar rough-outs c. $1.4 \mathrm{~km}$ southwest of Group 3 at Site 52 (Fig. 57).

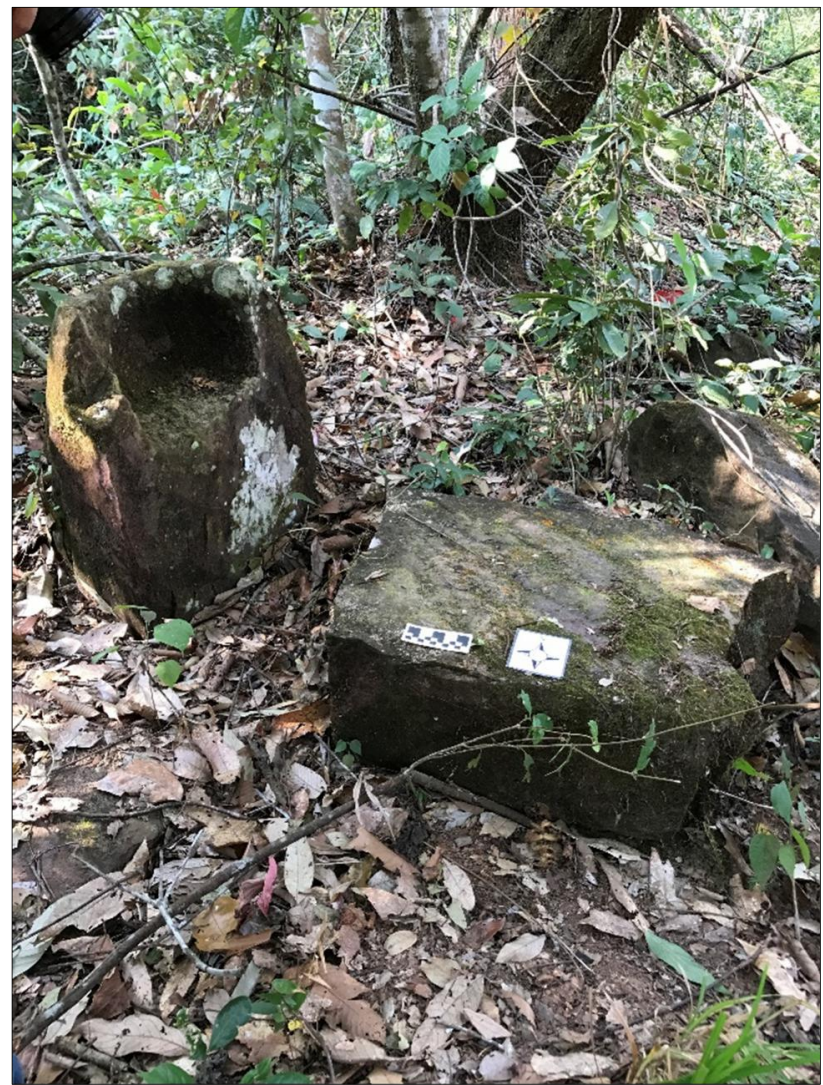

Figure 57. Incomplete jars at Q3 (photo PoJAP).

Site 52 Q4

Q4 comprises 4 jars/rough-outs south of Group 4 at Site 52. A complete inventory of the site was not possible given time constraints.

\section{Site 52 Q5}

Q5 is a possible quarry near a seasonal pond at elevation. The number of jars and rough-outs were not inventoried due to time constraints. This site is c. $1.09 \mathrm{~km}$ southeast of Group 3 at Site 52.

\subsection{DISCUSSION}

In examining the location of most of the jar sites it seems there is a preference for elevated positions for the most part. Most of the known sites are located atop mountains or hills with expansive views of the surrounding landscape. The most famous site, Site 1, is anomalous in this regard. Most of the megalithic sites across Xieng Khouang are found in mountainous areas surrounding the lower elevation plains of the Province although geospatial analysis is needed to confirm this observation.

Most of the identified jar sites have modest numbers of jars. As the numbers of jars at most sites is unconfirmed it is difficult to provide accurate estimates on the distribution of jar numbers by site. However, based on the data that is available regarding jar numbers at present, it is apparent that most sites comprise under 20 megaliths. About 16 sites have between 20-60 jars and three sites have over 200. These latter, sites 1,3 and 52 , are by far the largest collections of jars comprising just over $46 \%$ of the total number of recorded jars.

The majority of sites comprise jars fashioned from sandstone but there are some instances of limestone, breccia, granite, conglomerate and andesite jars. Evidence for decoration on the jars is absent save one jar at Site 1 which boasts a human figure in low relief although this theme was found on two associated stone discs and a ceramic vessel (excavated from Site 1 by Nitta (1996)). There is some differentiation in the size and style of the jars found and they range in height and diameter between one to three $\mathrm{m}$ (Van Den Bergh and Luangaphay 2008). Six rim styles have been identified including those with a flat rim, a recessed inner rim, an outer rim, a recessed inner rim with an outer rim, a prominent rim and a collar rim (Genovese 2015). It could be argued that three of these styles (the outer rim/prominent rim and collar rim) could be conflated as they are basically the same type but with variations in the height of the collar. The fact that many of the jars were carved with rims has led to speculation that the jars may, at one time, have had lids (Colani, 1935:203; Van Den Bergh and Luangaphay, 2008; Genovese 2015). Some sites indubitably have stone lids, such as Site 52 where elaborate caps have been carved from stone, some decorated in the round but for the most part no lids have been identified at the majority of jar sites. This has led to further speculation that the discs often found at jar sites served as lids but this is unlikely as they are often too large and cannot be accommodated by the rims in most cases. The stone discs are, in some instances, used as grave markers and human interments have been found beneath them (Colani 1935:209; Van Der Bergh and Luangaphay 2008; O'Reilly and Shewan, forthcoming). Other grave markers are also known in the form of unaltered boulders, often imported to the jar sites. Boulders have been found to mark the location of subterranean ceramic jar burials (Nitta, 1996:16; Sayavongkhamdy and Bellwood 2002:106; Shewan, O'Reilly and Luangkhoth 2016; O'Reilly and Shewan, forthcoming).

Evidence of habitation sites that relate to these jar fields remains fugitive as does any evidence of the culture group that created them or, indeed, when they were created. Recent research efforts by the joint Lao-Australian team have focused on addressing these issues targeting a potential habitation site identified by Sayavongkhamdy (pers. comm.) near the Phonsavan airport and field surveys have been undertaken although this task is complicated by 


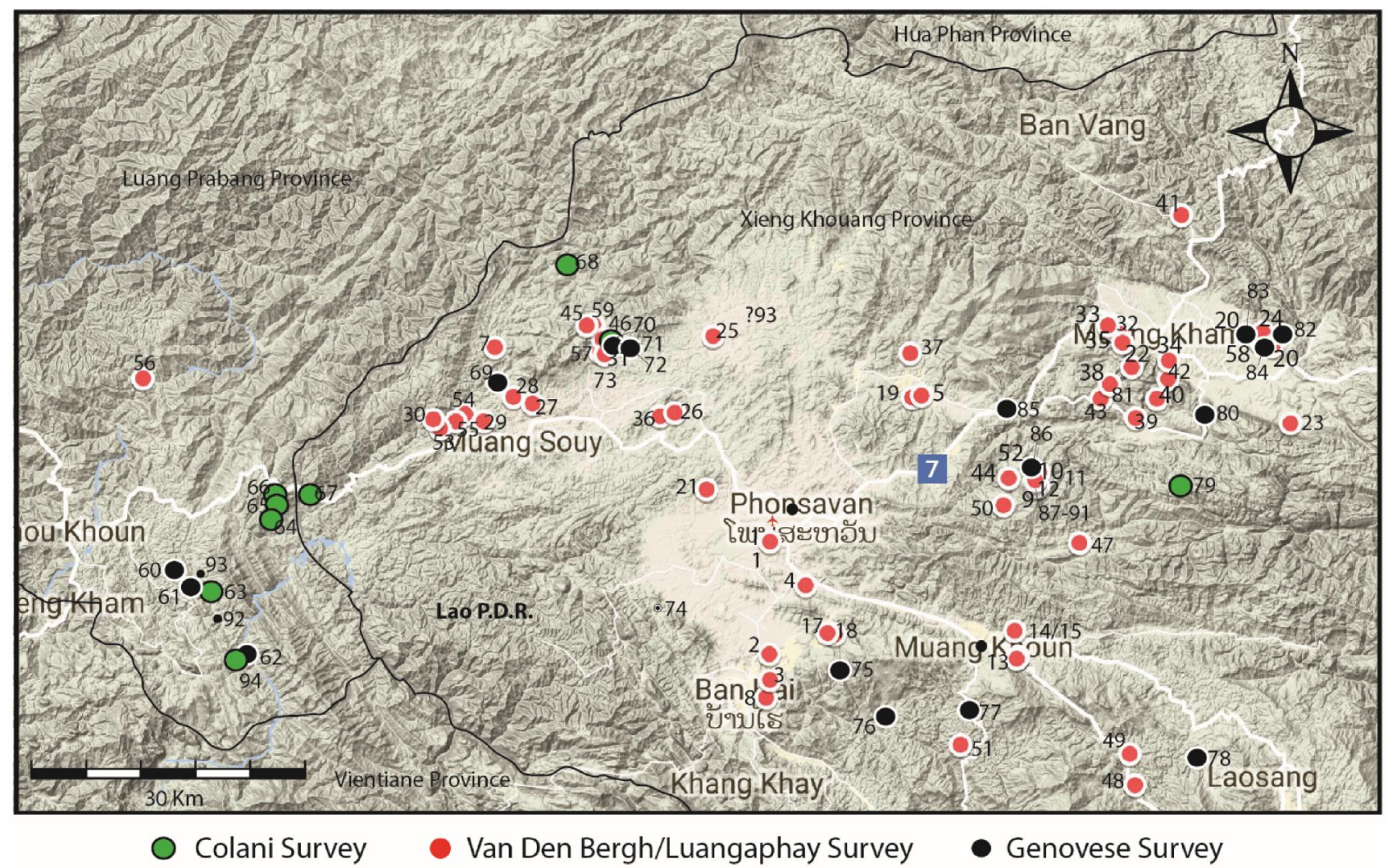

Figure 58. All known megalithic jar sites in Laos.

1. Site 1, 2. Site 2, 3. Site 3, 4. Site 4, 5. Site 5, 7. Site 7, 8. Site 8, 9. Site 9, 10. Site 10, 11. Site 11, 12. Site 12, 13. Site 13, 14. Site 14, 15. Site 15, 16. Site 16, 17. Site 17, 18. Site 18, 19. Site 19, 20. Site 20, 21. Site 21, 22. Site 22, 23. Site 23, 24. Site 24, 25. Site 25, 26. Site 26, 27. Site 27, 28. Site 28, 29. Site 29, 30. Site 30, 31. Site 31, 32. Site 32, 33. Site 33, 34. Site 34, 35. Site 35, 36. Site 36, 37. Site 37, 38. Site 38, 39. Site 39, 40. Site 40, 41. Site 41, 42. Site 42, 43. Site 43, 44. Site 44, 45. Site 45, 46. Site 46, 47. Site 47, 48. Site 48, 49. Site 49, 50. Site 50, 51. Site 51, 52. Site 52, 53. Site 53, 54. Site 54, 55. Site 55, 56. Site 56, 57. Site 57, 58. Site 58, 59. Site 59, 60. J52, 61. J50, 62. J51, 63. Eleven Jars, 64. Sud te Kéo Tane, 65. Circular Path, 66. Kéo Tane, 67. Est de Kéo Tane, 68. Pou Suong, 69. Ban Sop?, 70. Unnamed, 71. Ban Naséo?, 72. J37, 73. J27, 74. Ban Phan,75. Pho Tsa Nghem, 76. Ban Phuong, 77. QS 49, 78. Ban Khek, 79. San Tiau?, 80. QS47, 81. J48, 82. J46, 83. J24, 84. J20, 85. J45, 86. Q10, 87-91. Newly discovered 'Q' sites. 92. Ban Chim, 93. Ban Nanan, 94. Sop Nam Miang? 95. Phou Naséo?.Omitted from this map are sites with unknown locations including San Kama, Ban Sopma and the 26 sites mentioned in the SPJP report.

the widespread presence of UXO. In the 2016 excavations at Site 1 human remains were recovered from which it is hoped DNA (aDNA) may be recovered potentially shedding some light on the ethnicity of those interred at the site. Dating remains a challenge and while dates have been obtained from the burial contexts surrounding the megalithic jars (O'Reilly and Shewan forthcoming) these dates do not necessarily relate to the jars themselves. Efforts by the authors to date the jars using optically stimulated luminescence have proved fruitless.

\subsection{CONCLUSION}

The inventory above, of known, documented megalithic sites in Laos demonstrates the pressing need for a comprehensive account of the heritage assets of Xieng Khouang, Luang Prabang and Hua Phan provinces. The total number of documented jar sites reported by various individuals stands at 93 (Fig. 58). A further 26 jar sites in Xieng
Khouang alone were reported by Van Den Bergh and Luangaphay (2008) but were not surveyed so this number remains unconfirmed until survey and documentation can be completed. The site of San Kama mentioned by Colani (1935) also remains unidentified. To date there are potentially, 118 sites in northern Laos with megalithic jars representing a significant culture about which very little is known. Recent research, such as that at Site 52 where four further sites with megalithic jars rough-outs, as well as unknown groups of jars at the site were discovered, indicates that there are probably many more undiscovered sites shrouded in the heavily forested upland landscape. In reviewing the data compiled from various sources including Colani, Van Den Bergh and Luangaphay and Genovese it is clear that the peoples who created the megalithic jars of northern Laos occupied and exploited an expansive territory. Further, the much less recognisable 'fields of stones' may also proliferate and no research has been undertaken on this aspect of the megalithic culture of northern Laos 
Table 1: Plain of Jars site inventory.

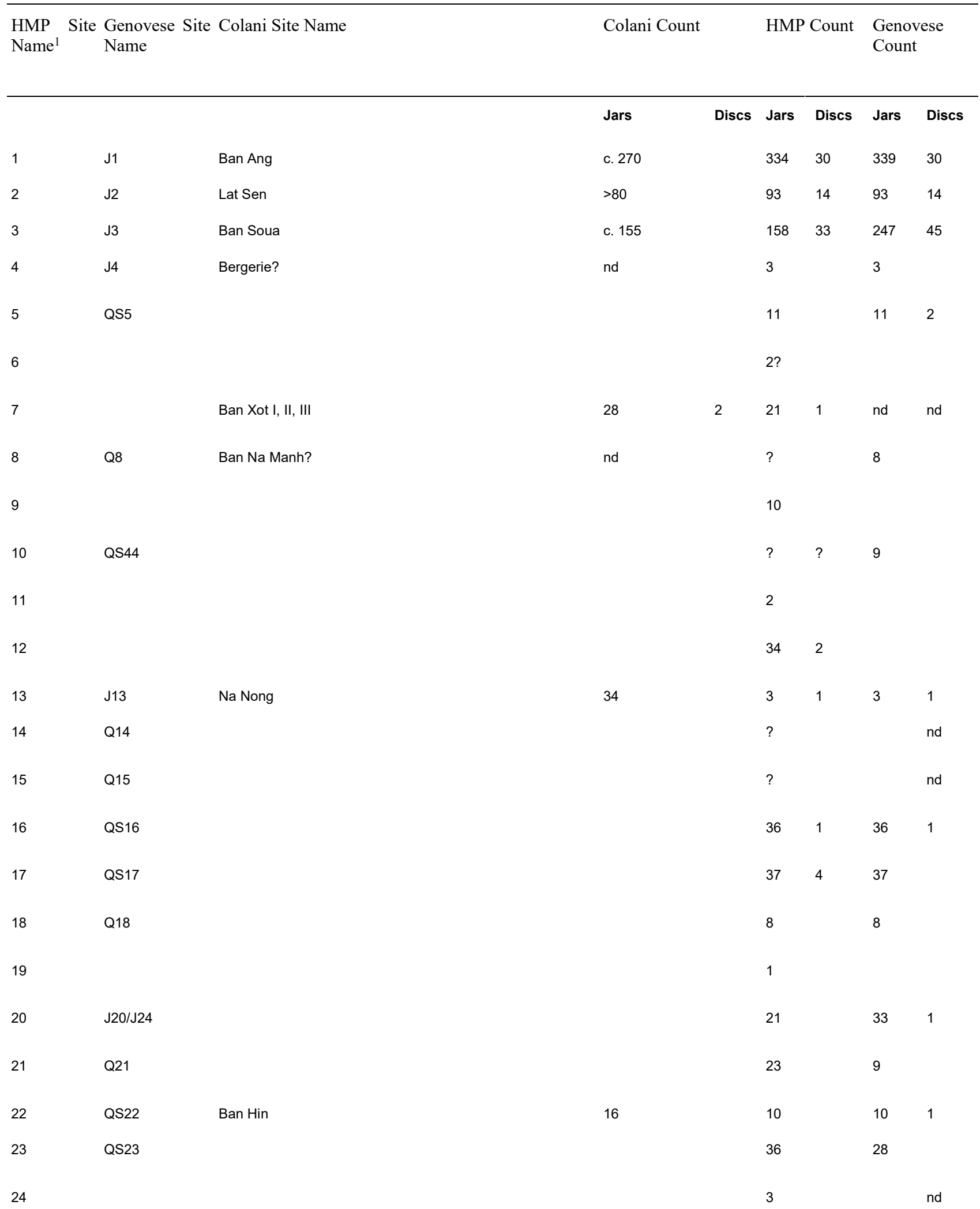

${ }^{1} \mathrm{HMP}=$ Heritage Management Plan - used by Lao government. 
J29

$\mathrm{J} 30 ?$
J26

Isolated jar at Ban Sak

Possibly Colani Eight jars near Ban Nam Ngum (no coords 8 given) although Genovese says this site has not been found.

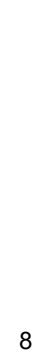

Ban Nam Ngum?

8

$\begin{array}{llll}14 & 2 & 16 & \\ & & & \\ \text { C. } & ? & 371 & 96 \\ 400 . & & & \end{array}$
c.
400. 
Ban Phuong

Ban Sop Ban Xot??? 


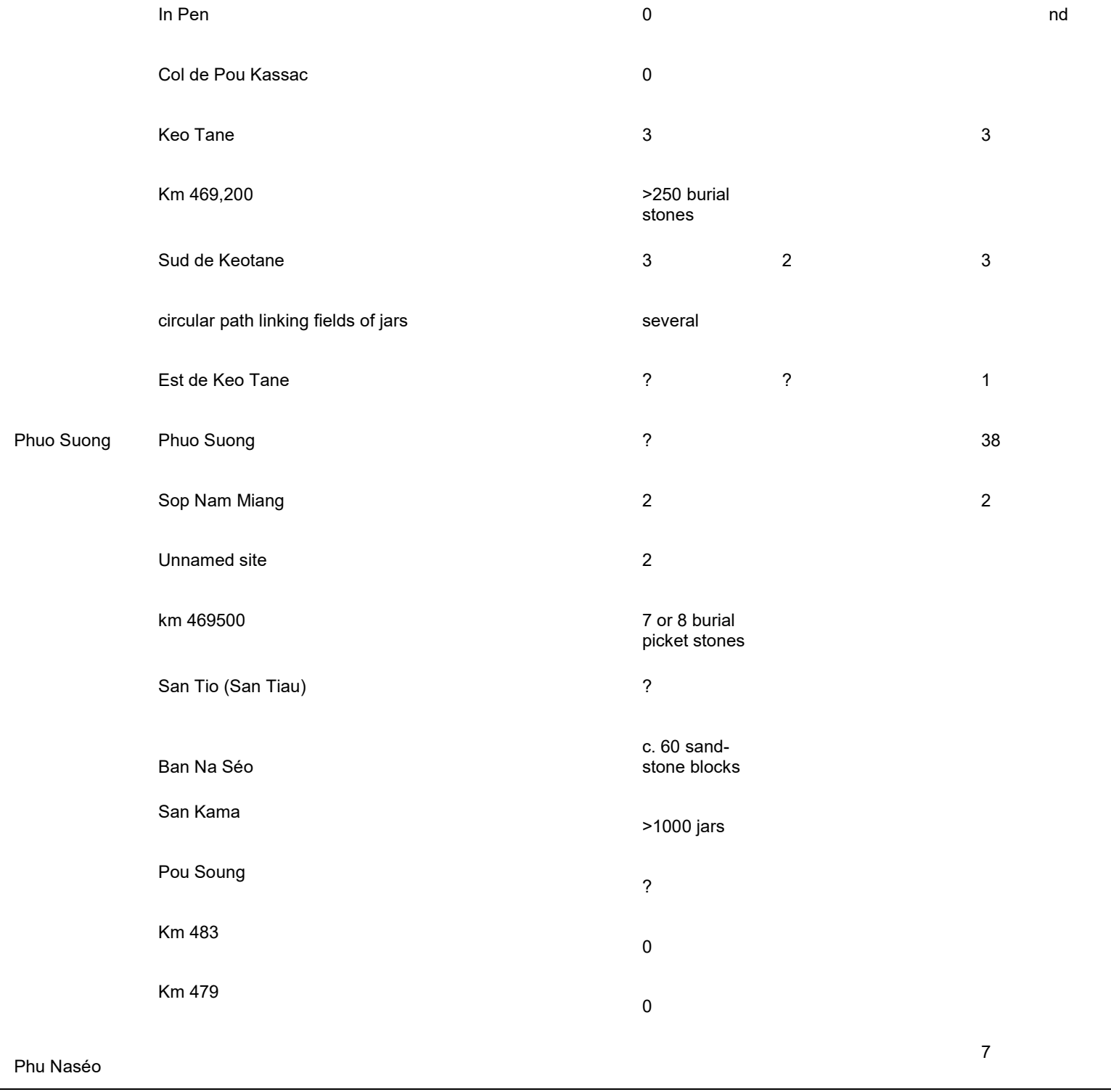

since Colani's time. Regrettably many of the 'fields of stones' sites she documented have since been destroyed but it is likely that many more exist that have been unrecognised.

Many questions remain regarding this culture including when the jars were created and whether the mortuary contexts discovered at several of the jar sites are contemporaneous to the jars, whether the mortuary contexts themselves (primary, secondary and ceramic jar burials) are contemporaneous or represent extended site utilisation). We also have no understanding of where the creators of the jars lived or how they transported the jars to their present location from the quarry sites. These questions form part of the renewed investigation of the jar sites.

\section{ACKNOWLEDGEMENTS}

Special thanks to Damian Evans and John Pollard for assistance in converting geographic coordinates provided by Colani and to the Department of National Heritage, Min- istry of Information, Culture and Tourism, Lao PDR government. This work was supported by the Australian Research Council [DP150101164].

\section{BIBLIOGRAPHY}

Baldock, J. and Van Den Bergh, J. 2009. Geological Mysteries of the Plain of Jars Begin to Unravel. Geol. Tod., Vol. 24:4 pp. $145-150$.

Barthélemy, F.P., Comte de. 1901. En Indo-Chine, 1896-1897, Tonquin, Haut Laos, Annam Septentrional, Plon-Nourrit, Paris.

Box, P. 2003. Safeguarding the Plain of Jars: Megaliths and Unexploded Ordnance in the Lao People's Democratic Republic Journal of GIS in Archaeology, Volume I. pp.92101.

Colani, M. 1934. Note sur des Mégalithes du Haut-Laos (Montagnes du Tran Ninh et des Hua Pan), BSPF, 31/7-8, pp. 335-352.

Colani, M. 1935. Mégalithes du Haut-Laos (Hua Pan, Tran Ninh), Ecol. Fran. Ext. Or., XXXV, Paris. 
Colani, M. 1940. Notice sur le champ de jarres de Song Méng (Tran Ninh), Bull. Ecol. Fran. Ext. Or., 40-40/2, Hanoi, pp. 495-496.

Genovese, R. 2014. Site Survey Preliminary Report, Phu Da Pho, Plain of Jars, Laos, February 2014 (https://www.academia.edu/6540396/Plain_of_Jars_Phu_Da_Pho_Laos).

Genovese, R. 2015. The plain of jars of north Laos: beyond Madeleine Colani. PhD Thesis. SOAS, University of London.

Khamphoumy, M. 2013. The Plain of Jars in Laos. Unpublished internal report for the Ministry of Information, Culture and Tourism, Division of Archaeological Research, Vientiane, Laos.

McCarthy, J. F. 1994. Surveying and Exploring in Siam, White Lotus Press, Bangkok (first published in 1900 by John Murray, London).

Maspéro, G. (ed.). 1929. Un Empire Colonial français - L'Indochine, Van Oest, Paris, 2 vols.

Nitta, E. 1996. Comparative Study on the Jar Burial Traditions in Vietnam, Thailand and Laos. Historical Science Reports, Kagoshima University 43:1-19.

O'Reilly, D. and L. Shewan (2016). The Mysterious Megalithic Jars of Central Laos. TAASA Review: J. Asian Art. Soc. of Aust. 25/4.

Parmentier, H. 1954. L'art du Laos (J. Leuba-Parmentier \& R. Dalet eds.), EFEO, 35, Paris, 2 vols.

Pavie, A. 1919. Mission Pavie: Indo-Chine 1879-1895, Géographie et Voyages VII, Journal de Marche (1888-1889), Événements du Siam (1891-1893), Ernest Leroux, Paris.

Raquez, A. 1902. Pages laotiennes, F.H. Schneider, Hanoi.

Rogers, P. 2002. Survey Training and Implementation of the Comprehensive Cultural Heritage Inventory. UNESCO Plain of Jars Cultural Heritage Documentation Project, Richard A Engelhardt, ed., UNESCO Regional Advisor for Culture in Asia and the Pacific, Bangkok.

Rogers P., R. Engelhardt, P. Box, J. Van Den Bergh, Samlane Luangaphay and Chantone Chantavong 2003. The UNESCO project: Safeguarding the Plain of Jars. In A. Karlström, and A. Källén (eds) Fishbones and Glittering Emblems: Southeast Asian Archaeology 2002. Stockholm: Museum of Far Eastern Antiquities.

Sayavongkhamdy, Thongsa, Peter S. Bellwood, and F. David Bulbeck. 2000. Recent archaeological research in Laos. Bull. Indo-Pac. Prehist. Assoc. 19:101-110.

Shewan, L., O'Reilly, D. and Luangkhoth, T., 2016. Recent Excavations at a Megalithic Jar site in Laos: Site 1 Revisited. Antiquity Project Gallery. June 2016; 90

Van Den Bergh, J. and Luangaphay, S. (ed.s) 2008. Plain of Jars Archaeological Landscape: Heritage Management Plan. Unpublished report submitted by Safeguarding Plain of Jars project for review to National Heritage Department of the Ministry of Information, Culture and Tourism. 